OPEN ACCESS

Edited by:

Vivian Kahl,

The University of Queensland,

Australia

Reviewed by:

Georgia Kafer,

University of the Sunshine Coast,

Australia

Jianwei Wang,

Tsinghua University, China

Bruno Paiva Dos Santos,

INSERM U1026 Bioingénierie

Tissulaire, France

*Correspondence:

Lara Barazzuol

l.barazzuo@@umcg.nl

Specialty section:

This article was submitted to

Signaling,

a section of the journal

Frontiers in Cell and Developmental

Biology

Received: 22 June 2021

Accepted: 18 August 2021

Published: 08 October 2021

Citation:

Cinat $D$, Coppes RP and

Barazzuol L (2021) DNA

Damage-Induced Inflammatory Microenvironment and Adult Stem

Cell Response.

Front. Cell Dev. Biol. 9:729136. doi: 10.3389/fcell.2021.729136

\section{DNA Damage-Induced Inflammatory Microenvironment and Adult Stem Cell Response}

\author{
Davide Cinat ${ }^{1,2}$, Robert P. Coppes ${ }^{1,2}$ and Lara Barazzuol ${ }^{1,2 *}$ \\ 1 Department of Biomedical Sciences of Cells and Systems, University Medical Center Groningen, University of Groningen, \\ Groningen, Netherlands, ${ }^{2}$ Department of Radiation Oncology, University Medical Center Groningen, University of Groningen, \\ Groningen, Netherlands
}

Adult stem cells ensure tissue homeostasis and regeneration after injury. Due to their longevity and functional requirements, throughout their life stem cells are subject to a significant amount of DNA damage. Genotoxic stress has recently been shown to trigger a cascade of cell- and non-cell autonomous inflammatory signaling pathways, leading to the release of pro-inflammatory factors and an increase in the amount of infiltrating immune cells. In this review, we discuss recent evidence of how DNA damage by affecting the microenvironment of stem cells present in adult tissues and neoplasms can affect their maintenance and long-term function. We first focus on the importance of self-DNA sensing in immunity activation, inflammation and secretion of pro-inflammatory factors mediated by activation of the cGAS-STING pathway, the ZBP1 pathogen sensor, the AIM2 and NLRP3 inflammasomes. Alongside cytosolic DNA, the emerging roles of cytosolic double-stranded RNA and mitochondrial DNA are discussed. The DNA damage response can also initiate mechanisms to limit division of damaged stem/progenitor cells by inducing a permanent state of cell cycle arrest, known as senescence. Persistent DNA damage triggers senescent cells to secrete senescenceassociated secretory phenotype (SASP) factors, which can act as strong immune modulators. Altogether these DNA damage-mediated immunomodulatory responses have been shown to affect the homeostasis of tissue-specific stem cells leading to degenerative conditions. Conversely, the release of specific cytokines can also positively impact tissue-specific stem cell plasticity and regeneration in addition to enhancing the activity of cancer stem cells thereby driving tumor progression. Further mechanistic understanding of the DNA damage-induced immunomodulatory response on the stem cell microenvironment might shed light on age-related diseases and cancer, and potentially inform novel treatment strategies.

Keywords: DNA damage, inflammation, microenvironment, immune response, stem cells, cancer

\section{INTRODUCTION}

Stem cells are undifferentiated cells essential for tissue growth and maintenance (Blanpain and Simons, 2013). They can be classified according to their origin in embryonic stem cells, induced pluripotent stem cells (iPSCs) and tissue-specific stem cells (also known as adult or somatic stem cells) (Shevde, 2012). Embryonic and iPSCs are pluripotent stem cells, derived from an early stage 
embryo and reprogramming of somatic cells, respectively, able to differentiate into any specialized tissue cell type (Kingham and Oreffo, 2013). On the other hand, tissue-specific stem cells are multi- or unipotent cells able to give rise to specialized cell type(s) present in a specific tissue and belonging to a particular lineage. Tissue-specific stem cells are present in small numbers in several adult tissues or organs ensuring tissue homeostasis and regeneration upon damage (Wagers and Weissman, 2004). Similarly to normal tissues, most tumors also possess a population of cells characterized by stem cell-like features that are defined as cancer stem cells (CSCs) (Coppes and Dubrovska, 2017). Like normal stem cells, CSCs have the ability to self-renew and generate differentiated cell types, which foster the growth and maintenance of many types of neoplasms alongside being often attributed to treatment resistance and cancer recurrence (Vitale et al., 2017).

Stem cells constantly receive signals from the surrounding microenvironment, also known as the stem cell niche, a 'home' that supports the maintenance and proper function of stem cells to ensure tissue homeostasis and respond to damage (Jones and Wagers, 2008). These niche signals can be either extrinsic, mediated by secreted factors, cell surface molecules/receptors, cell-cell interactions and gap junctions, or intrinsic resulting in persistent intracellular changes in the stem cell epigenetic profile and metabolism (Pennings et al., 2018). Additionally, the stem cell microenvironment is composed by specific cells, often distributed in a defined spatial order, such as differentiated cells, stromal cells, immune cells, vasculature- and nervous systemrelated cells (Figure 1, left panel). These cells work together to ensure structure and appropriate reception of local as well as systemic signals (Lane et al., 2014).

The non-cellular physical properties of the microenvironment itself, such as the extra-cellular matrix (ECM) molecule composition and oxygen levels, can also affect stem cell behavior by affecting stem cell related pathways. A classic example of this is the role of the YAP/TAZ signaling pathway in mechanotransduction (Dupont et al., 2011). While hypoxia inducible factors (HIFs) have been shown to modulate other stem cell-related pathways, such as Notch signaling (Keith and Simon, 2007) and autophagy (Li et al., 2015).

The structure and function of the stem cell microenvironment have been extensively reviewed in Jones and Wagers (2008). Additionally, notions described for the hematopoietic stem cell (HSC) niche (Mendelson and Frenette, 2014; Crane et al., 2017; Pinho and Frenette, 2019), such as the maintenance of HSCs via specific factors secreted by endothelial and stromal cells as well as immune cells and sympathetic nerve fibers, can be applied to solid tissues. Importantly, the stem cell microenvironment has been shown to be a dynamic compartment rapidly adapting in response to insults, diseases (including oncogenesis) and aging (Scadden, 2006). Aging is a pleiotropic process characterized by multiple factors, including increased levels of DNA damage (Schumacher et al., 2021) due to various sources (as described in the following section) coupled with a reduced cellular DNA repair capacity.

Throughout life stem cells are significantly exposed to DNA damage due to their longevity and functional requirements, such as ensuring tissue homeostasis and replenishment of damaged or lost cells via prolonged proliferation (self-renewal) and differentiation (Mandal et al., 2011; Schumacher et al., 2021). In particular, cell proliferation is intrinsically related to replication stress, a phenomenon characterized by DNA synthesis slow down and stalled replication forks that in turn can result in DNA damage as previously shown in aged HSCs (Flach et al., 2014).

In this review, we describe how the recently discovered immunomodulatory responses initiated by DNA damage can

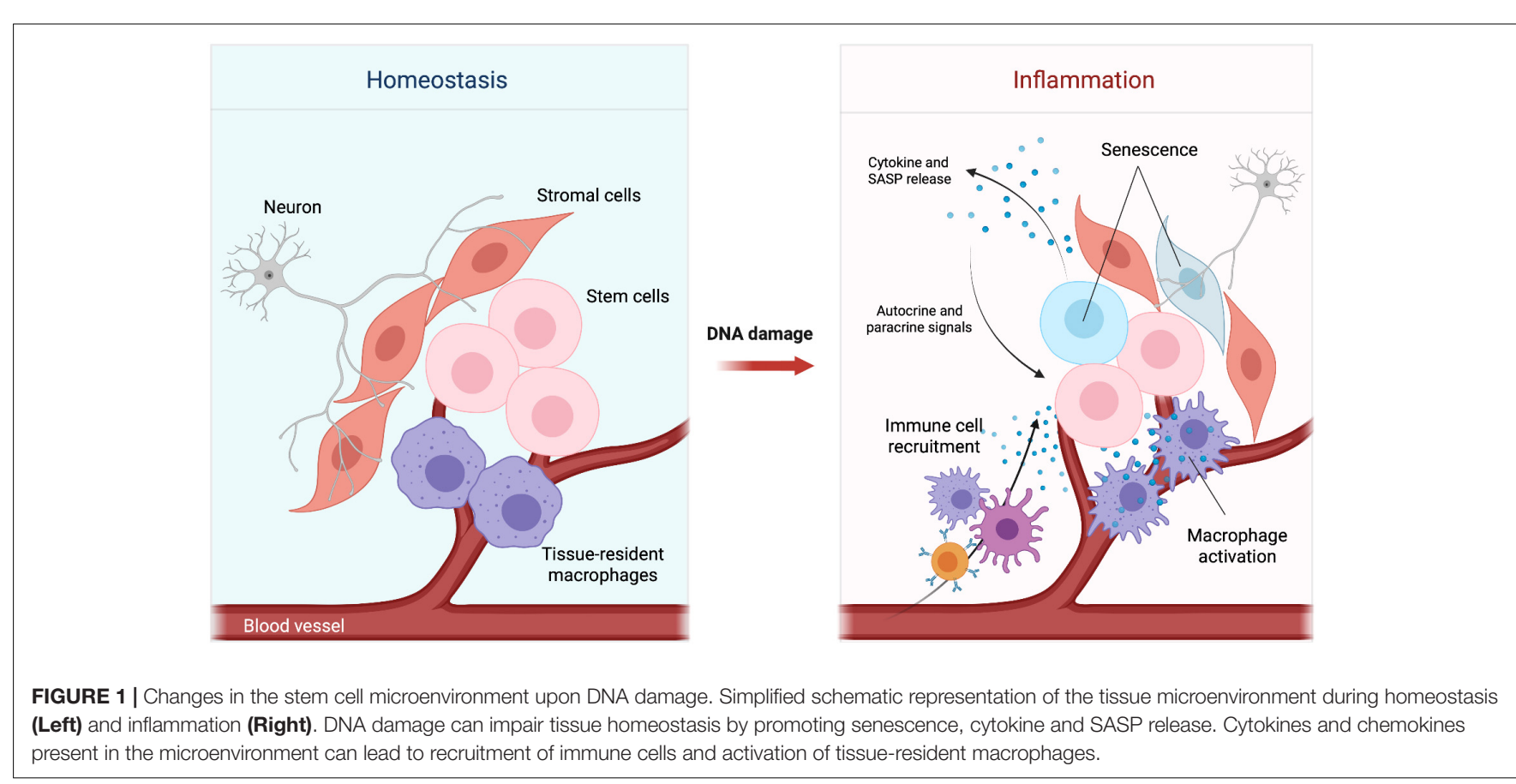


alter different aspects of the stem cell microenvironment thereby affecting the function of both tissue-specific and cancer stem cells. The main cytosolic nucleic acid sensing pathways activated upon cytosolic DNA and RNA recognition and involved mechanisms, which can induce microenvironmental changes that affect stem cell function, are discussed. Additionally, an overview of immune cell infiltration and the importance of DNA damage-induced cellular senescence in tissue homeostasis, stem cell regeneration potential and CSC recognition is provided.

\section{DNA DAMAGE IN ADULT STEM CELLS}

Different endogenous sources of DNA damage can affect adult stem cells and their microenvironment, such as reactive oxygen species (ROS) produced by metabolic intermediates and dysfunctional mitochondria, alcohol and endogenous aldehydes, glycolytic by-products and advanced glycation end products, replication stress depending on the proliferation status of the cells, transcriptional disruption and telomere shortening. Importantly, although it is difficult to reliably assess such endogenous sources of DNA damage, they are thought to increase with age (Chaudhuri et al., 2018; Schumacher et al., 2021). As a result of such physiological cellular processes, in a day each cell may be exposed to nearly 100,000 DNA lesions, including different types of base modifications, single-strand breaks (SSBs) and double-strand breaks (DSBs) (Madabhushi et al., 2014). Additionally, external sources can lead to DNA damage, such as ionizing radiation (most commonly UV and X-rays) and certain chemicals. This is especially relevant for CSCs and normal tissue stem cells co-exposed to DNA damaging cancer therapies, such as radiotherapy and many chemotherapeutic agents.

In response to DNA damage cells initiate a coordinated series of events known as the DNA damage response (DDR), which encompasses various DNA repair pathways, cell cycle checkpoints and cell death pathways, and extensively described in Jackson and Bartek (2009). The DDR initiates with the sensing of DNA damage by protein complexes and kinases, and the subsequent signaling mediated by post-translational modifications, such as protein phosphorylation. Although these complex molecular mechanisms can vary between different types of somatic cells and stem cells (Vitale et al., 2017), the main DNA repair pathways are usually conserved and depending on the type of DNA lesion comprise: base excision repair (BER) and single strand break repair (SSBR), which promote the repair of small DNA lesions, such as base modifications and SSBs, through the excision of damaged bases; nucleotide excision repair (NER), which promotes the repair of DNA lesions such as adducts and structures that distort the DNA double helix; DNA mismatch repair (MMR), essential for the correction of base mismatches and small insertions or deletions; non-homologous end joining (NHEJ) and homologous recombination (HR), which are the classical pathways involved in DSB repair (Jackson and Bartek, 2009; Scully et al., 2019). Collectively with DNA repair, DNA damage signaling can lead to the activation of cell cycle checkpoints, which are points throughout the cell cycle in which movement is paused or slowed down to allow time for the cell to repair the damage, or to the induction of cell death, mainly by apoptosis and necrosis, or to an irreversible state of growth arrest so-called cellular senescence (Jackson and Bartek, 2009).

As stem cells age, DNA damage coupled with a reduced DNA repair capacity has been shown to contribute to the development of age-related disorders from cancer to tissue degeneration (Behrens et al., 2014). Oncogenesis is often a result of aging due to DNA damage misrepair and the consequent accumulation of mutations (Jeggo et al., 2016). A decline in stem cell function has also been related to defects in different DDR components, which in the HSC system cause reduced self-renewal and long-term exhaustion leading to bone marrow failure and anemia (Vitale et al., 2017) or pre-mature differentiation in non-HSCs such as neural stem cells (NSCs) (Barazzuol et al., 2017) and melanocyte stem cells (McSCs) (Inomata et al., 2009). Additionally, as a consequence of DNA damage, the microenvironment, the resulting signaling pathways and infiltrating cells adapt to this new state (Figure 1, right panel).

Although long-term self-renewal and differentiation capabilities are the defining features of stem cells, their regeneration potential is restricted to a definite number of times during the lifespan of an organism (Pazhanisamy, 2009). This can represent an important limitation; indeed, stem cells can be induced to self-renew more often upon damage or genotoxic stress, such as irradiation (Sémont et al., 2006). A prolonged activation of this process can inevitably lead to stem cell exhaustion and loss of tissue homeostasis maintenance (Pazhanisamy, 2009). Furthermore, many types of stem cells, including HSCs and NSCs (Barazzuol et al., 2017; Schumacher et al., 2021), reside in a quiescent state, which, although limits the amount of endogenous DNA damage (such as that caused by replication stress or metabolic by-products), may lead to the accumulation of DNA lesions due to the restricted availability of error prone NHEJ in non-cycling cells with subsequent stem cell functional impairment and premature aging (Schumacher et al., 2021). Moreover, DNA damage upon genotoxic stress has been shown to promote premature differentiation of McSCs, hair follicle stem cells and NSCs, thus preventing their expansion (Inomata et al., 2009; Matsumura et al., 2016; Barazzuol et al., 2017). However, it remains unclear whether DNA damage-induced premature differentiation can be linked to the DNA damage-mediated inflammatory process. Defects in DNA repair as in rare genetic disorders can also promote the decline of tissue stem cell functions leading to age-related diseases, such as bone marrow failure, and tumor formation via the generation of CSCs (Biechonski et al., 2017; Vitale et al., 2017; Tiwari and Wilson, 2019). For example, similarly to other stem cells, NSCs have the ability to migrate from their niche in order to differentiate and promote the repair of damaged brain tissue; however, abnormalities in this process may lead to stem cell transformation and glioblastoma formation (Vescovi et al., 2006). These events can be extended also to other tissues and organs, such as skin, liver, muscle and gut, 
whose repair depends on the activity of specific adult stem cells (Kenyon and Gerson, 2007).

\section{INTERPLAY BETWEEN DNA DAMAGE AND INFLAMMATION IN THE STEM CELL MICROENVIRONMENT}

One of the main roles of the immune system is to mediate the recognition of dangerous and invasive elements through the expression of specific pattern recognition receptors (PRRs). These elements can be distinguished in pathogen-associated molecular patterns (PAMPs) and damage-associated molecular patterns (DAMPs) (Gong et al., 2019). PAMPs are exogenous components that are unique to invading microorganisms, such as specific membrane-associated lipids, lipopolysaccharides (LPS) and lipoglycans (Silva-Gomes et al., 2014). In contrast, DAMPs are endogenous molecules released by damaged or dying cells and are not related to a pathogen infection (Gong et al., 2019). Although PAMPs and DAMPs have different origins, the recognition of such molecules is mediated by similar PRRs, such as Toll-like receptors (TLRs), NOD-like receptors, intracellular nucleic acid-sensing receptors and C-type lectin receptors. Activation of these proteins is essential for the secretion of cytokines and attracting innate immune cells into the infected or damaged tissue (Gasteiger et al., 2017). The innate immune system can then intervene with cell-dependent mechanisms, such as phagocytosis, cytotoxicity and secreted factors, in order to eliminate the pathogens or damaged cells (Gasteiger et al., 2017). Several in vitro and in vivo studies have demonstrated that an aberrant activation of these mechanisms can trigger the host immune response leading to inflammatory events and autoimmune diseases (Nakad and Schumacher, 2016). Interestingly, receptors and adaptor proteins related to DAMP and PAMP recognition processes strongly overlap and interconnect often in a positive feedback loop. This tight relation might explain why infection as well as stress factors like DNA damage can trigger the activation of similar inflammatory pathways leading to pro-inflammatory cytokine release and immunity activation (Jounai et al., 2013; Foell et al., 2007; Paludan and Bowie, 2013).

It is well established that in normal physiological conditions DNA is largely located within the nucleus and mitochondria. However, DNA leakage within the cytosol can occur as result of adverse events, such as DNA damage, triggering the induction of specific cytosolic DNA sensors and activation of DAMPrelated immune responses (Ishikawa et al., 2009; MacKenzie et al., 2017; Maekawa et al., 2019). Genotoxic events are usually accompanying by the formation of micronuclei into the cytoplasm, small extra-nuclear bodies formed by lagging chromosomes and chromosome fragments upon mitotic errors or DNA damage (Kwon et al., 2020). Importantly, due to defects in nuclear lamina organization (Hatch et al., 2013), the envelope of these isolated nuclear structures is fragile (Kwon et al., 2020). It has been shown that its rupture can lead to release of the micronuclear content into the cytoplasm with consequent chromothripsis (a mutational process characterized by the shattering and reassembly of a chromosome from a micronucleus) (Crasta et al., 2012; Koltsova et al., 2019). Alongside these processes, ruptured micronuclei have also been linked with the activation of various cytoplasmic nucleic acid sensors that boost the production of pro-inflammatory cytokines and activate the immune response (Crasta et al., 2012; MacKenzie et al., 2017). Interestingly, the activation of these pathways reflects a sign of microbial infections, which also alert the host innate immune system to mount a defense response.

These pro-inflammatory events can have important consequences on a variety of cell types, including stem cells, which function is modulated by their microenvironment (Voog and Jones, 2010). In fact, it has been shown that stem cell activity and their ability to self-renew can be strongly affected by either stress events, such as oxidative stress (Vono et al., 2018), or by chronic inflammatory diseases, such as bone marrow failure (Pronk et al., 2011; Vono et al., 2018). These events lead to the release of specific cytokines and chemokines into the microenvironment with consequent abnormal stem cell proliferation, mobilization and differentiation as well as premature quiescence and self-renewal decline (Jahandideh et al., 2020). Thus, excessive production and release of pro-inflammatory cytokines upon DNA damage can highly affect the stem cell regeneration capacity contributing to long-term dysfunction in aging tissues, including skin, bone marrow and adipose tissue (Crop et al., 2010; Shin et al., 2017; Hormaechea-Agulla et al., 2020).

Like normal tissue-specific stem cells, also CSCs can be influenced by changes in their surrounding microenvironment; indeed, it has been shown that pro-inflammatory stimuli are an essential component of the CSC niche (Zhang S. et al., 2018) able to potentially alter their function. The presence of inflammatory cytokines can have conflicting effects on CSCs. Growing evidence suggest that inflammation may be an important source of tumor progression and CSC expansion (Jeong et al., 2018), while other studies showed that specific type of cytokines, in particular interferons, can exert anti-tumor activity and obstruct angiogenesis (Martin-Hijano and Sainz, 2020).

\section{Cytosolic DNA Sensors and STING Activation}

Cytokines are in fact powerful mediators of stem cell function and their wide range of effects highlights the importance of DNA-sensing pathways, and activation and release of inflammatory molecules. In particular, one of the main adaptor proteins activated upon cytosolic DNA recognition and essential for the initiation of these inflammatory responses is stimulator of interferon genes (STING) (Ishikawa and Barber, 2008).

STING has been identified as an essential component for the initiation of innate immune signaling processes following activation of pathways related to cytosolic nucleic acid recognition (Ishikawa and Barber, 2008). The activation of this endoplasmic reticulum adaptor protein is essential for the triggering of transcription pathways and efficient production of type 1 interferon (IFN1) in several mammalian cell types (Ishikawa and Barber, 2008; Ishikawa et al., 2009). Specifically, 
STING activation promotes the nuclear translocation of the transcription factors NF- $\kappa$ B and IRF3 leading to cytokine production and innate immune gene transcription with a strong impact on cell fate and tissue homeostasis (Yum et al., 2021) (Figure 2). The specific mechanisms and pathways involved in NF- $\kappa \mathrm{B}$ and IRF3 activation, cytokine release, IFN1 expression and immunity regulation have been extensively reviewed in Liu et al. (2017) and Jefferies (2019).

Upon conformational changes, STING translocates to the Golgi apparatus thereby inducing the activation of IRF3 and $\mathrm{NF}-\kappa \mathrm{B}$, which function together in order to promote the transcription of cytokines like IFN1 (Ablasser and Chen, 2019; Li and Chen, 2018).

Interferons are a group of cytokines able to modulate the immune response and related inflammatory events. IFN1 shows autocrine, paracrine, and systemic functions and upon interaction with its receptor is able to induce the expression of more than 200 interferon stimulated genes (ISGs), which reinforce the expression of IFN1 leading to inflammation and innate immune signaling activation (Dunphy et al., 2018; Lee and Ashkar, 2018; Martin-Hijano and Sainz, 2020). Although the secretion of IFN1 can be beneficial for the resolution of viral infection events, the chronic exposure to this cytokine can influence stem cell proliferation and thereby induce functional defects. For example, chronic expression of IFN1 as a consequence of DNA damage has been shown to be a critical mechanism that connects DNA damage accumulation with premature aging and inhibition of intestinal stem cell function both in vitro and in vivo (Yu et al., 2015). Furthermore, IFN1 was shown to be implicated in proliferation and exhaustion of HSCs, and suppression of IFN signaling safeguards stem cell self-renewal and differentiation capacity providing the basis for potential improvements of bone marrow transplantation (Sato et al., 2009). Due to the large spectrum of ISGs produced upon IFN1 activation, the presence of this cytokine might be critical for the treatment of some cancer types

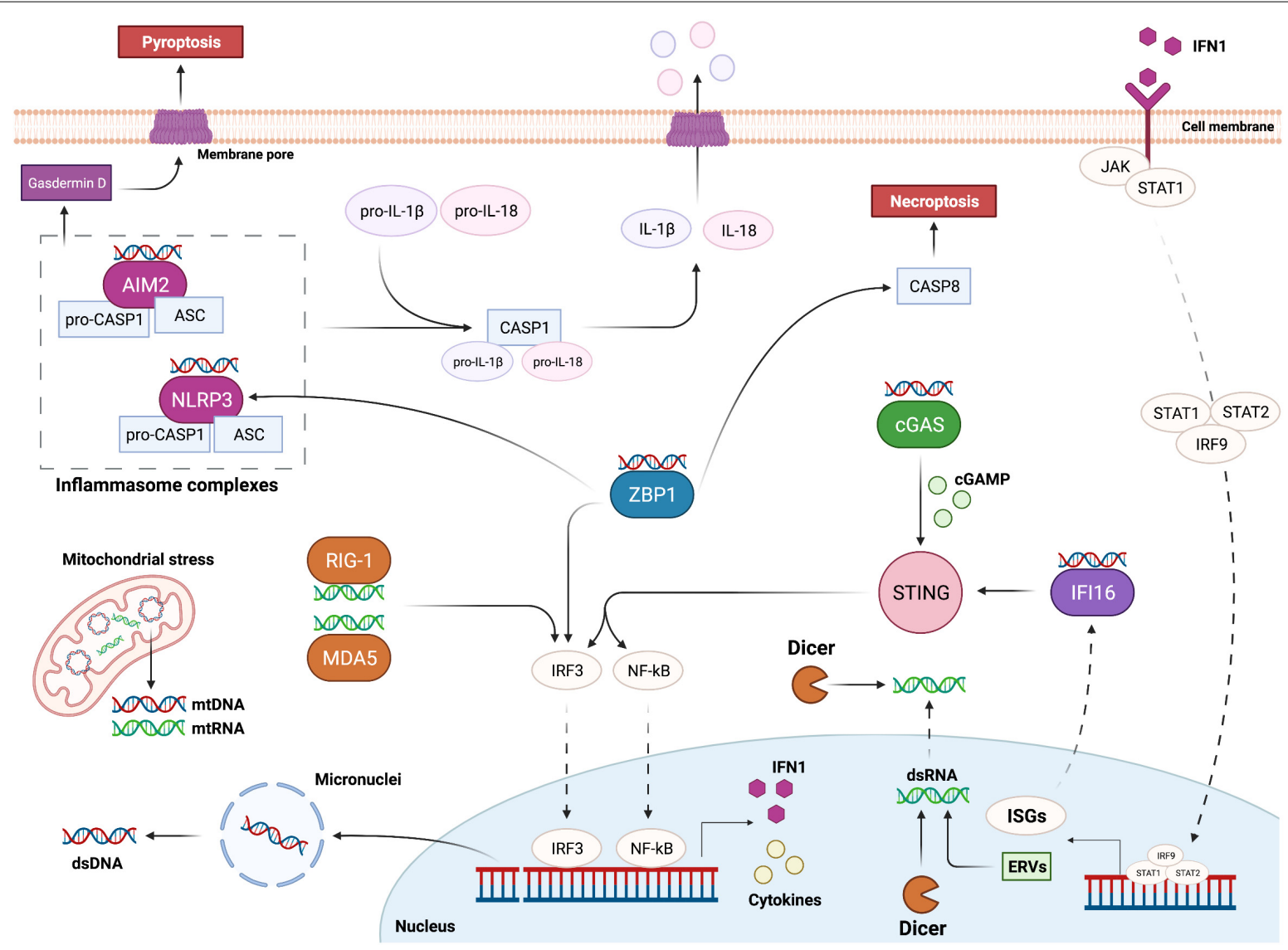

FIGURE 2 | Overview of the main pathways responsible for cytosolic nucleic acid recognition. DNA damage can trigger the formation of micronuclei and the release of double stranded DNA (dsDNA) into the cytoplasm. Mitochondria can also be a source of cytoplasmic DNA and RNA upon genomic stress. AlM2 and NLRP3 are part of two distinct inflammasome complexes, responsible for the bioactivation of Caspase-1 (CASP1); activated CASP1 in turn cleaves and promotes the activation of IL-1 $\beta$ and IL-18, which leave the cell upon inflammasome-mediated pyroptosis. cGAS is the main protein responsible for cytoplasmic dsDNA recognition; upon dsDNA binding cGAS promotes the formation of cGAMP, which binds and activates STING; STING in turn promotes the activation of IRF3 and NF-kB transcription factors responsible for the expression of IFN1 and various cytokines. IFN1 is then able to leave the cell and interact with its receptor; this interaction leads to STAT1, STAT2 and IRF9 complex (ISGF3) translocation into the nucleus and transcription of interferon stimulated genes (ISGs). ISGF3 activation can also lead to expression of ancestor endogenous retroviruses (ERVs) in form of double stranded RNA (dsRNA). Cytoplasmic dsRNA is recognized by RIG-1 and MDA5, which trigger the activation of IRF3. On the other hand, Dicer can sense and cleave both cytoplasmic and nucleic dsRNA. IFI16 is an ISG able to recognize dsDNA and activate STING. ZBP1 promotes IRF3 and NLRP3 activation, and Caspase-8 (CASP8)-mediated necroptosis upon recognition of Z forms of dsDNA. 
leading to the regression of CSCs and an overall decrease in tumor viability (Doherty et al., 2017; Martin-Hijano and Sainz, 2020). In fact, IFNs have been shown to impede tumor expansion by inducing prolonged cell cycle arrest and angiogenesis downregulation (Shang et al., 2011). Furthermore, IFNs are fundamental regulators of the immune response against tumors as exemplified by the IFN1-mediated immunogenicity of tumor cells increasing the immune system recognition (Martin-Hijano and Sainz, 2020).

One of the main proteins related to genotoxicity and mediation of immune responses upon cytosolic double-stranded DNA (dsDNA) recognition is the DNA-sensing enzyme cyclic guanosine monophosphate-adenosine monophosphate synthase (cGAS) (Table 1). Activated cGAS promotes the conversion of ATP and GTP into cyclin GMP-AMP (cGAMP), which binds and activates STING (Xia et al., 2016).

In addition to cGAS, other key DNA sensors are known to be important modulators of STING-dependent IFN1 production (Table 1). An example is the IFN $\gamma$-inducible protein 16 (IFI16), which can recognize both cytosolic and nuclear dsDNA (Almine et al., 2017). Importantly, this protein is not only a DNA sensor but it is itself an ISG, and the activation of this positive feedback loop can further enhance the inflammatory response and immune activation triggered by DNA damage and cytosolic DNA recognition (Dunphy et al., 2018) (Figure 2). Hence, excessive accumulation of IFI16 may have important consequences on IFN1-related autoimmune diseases, such as systemic lupus erythematosus and Sjogren syndrome ( $\mathrm{Li}$ et al., 2019). Interestingly, a recent study showed that upon etoposide-induced DNA damage, DNA damage response factors, such ATM and PARP1, are able to activate p53 and TRAF6, which assemble into a protein complex together with IFI16 outside the nucleus. This complex can then activate STING in a non-canonical way leading to a more pronounced activation of NF-кB compared to IRF3 (Dunphy et al., 2018). Importantly, a higher induction of $\mathrm{NF}-\kappa \mathrm{B}$ can result in the expression of various pro-inflammatory related-genes, adhesion molecules and cell cycle regulators, such as IL-6, TNF $\alpha$, RANTES, CXCL10, MMPs and BCL-2 family proteins (Liu et al., 2017; Dunphy et al., 2018).

Both canonical and non-canonical activations of NF- $\kappa$ B are known to be involved in immune and inflammatory responses. Promotion of this family of transcription factors leads to expression of a broad range of molecules leading to inflammation as well as cell survival, proliferation, angiogenesis, cell adhesion and metastasis (Liu et al., 2017). It has been observed that genotoxic stress and NF- $\mathrm{B}$ autocrine and paracrine signaling are able to influence mesenchymal and hematopoietic stem cell characteristics affecting their proliferation capacity and regeneration potential (Ping et al., 2019). Furthermore, chronic exposure to inflammatory molecules induced through activation of NF- $\mathrm{B}$ has been associated with uncontrolled NSC proliferation with consequent risk of mutagenesis and hence cancer development (Widera et al., 2008). NF-кB is also known to be a powerful activator of immune cells through the secretion of several chemokines and cytokines (Hayden et al., 2006). Immune cell infiltration in normal tissue can compromise tissue homeostasis and physiological function. Indeed, a recent study showed that loss of sensory neurons and decreased olfactory function in chronic rhinosinusitis can be linked to a prolonged inflammatory state alongside immune cell infiltration (Chen M. et al., 2019). NF- $\kappa B$ deregulation can indeed lead to overexpression of specific cytokines and chemokines, such as CCL19 and CCL20, with consequent recruitment and proliferation of macrophages and $\mathrm{T}$ cells causing a loss in olfactory mucosa horizontal basal stem cell regeneration potential and tissue homeostasis in vivo (Chen M. et al., 2019).

TABLE 1 | List of DNA and RNA sensors mentioned in this review, the relative downstream effect and examples of stem cell types shown to express these sensors.

\begin{tabular}{|c|c|c|c|c|c|}
\hline Sensor & Ligand & Source & Downstream effect & Stem cell type & References \\
\hline cGAS & dsDNA & $\begin{array}{l}\text { Virus infection; cytosolic } \\
\text { self-DNA; micronuclei }\end{array}$ & $\begin{array}{l}\text { STING activation; NF-kB } \\
\text { activation; IFN1 expression }\end{array}$ & $\begin{array}{l}\text { MSCs; HSCs; stem cell-like } \\
\text { CD8+ T cells; embryonic stem } \\
\text { cells }\end{array}$ & $\begin{array}{l}\text { Yang et al., 2015; Li et al., 2020; } \\
\text { Sharma et al., 2020; Zheng et al., } \\
2020\end{array}$ \\
\hline $\mathrm{IFI} 16$ & $\begin{array}{l}\text { dsDNA or } \\
\text { ssDNA }\end{array}$ & $\begin{array}{l}\text { Virus infection; cytosolic } \\
\text { self-DNA; micronuclei }\end{array}$ & $\begin{array}{l}\text { Modulation of STING activity; } \\
\text { NF-kB activation; IFN1 } \\
\text { expression }\end{array}$ & Hair follicle stem cells; HSCs & $\begin{array}{l}\text { Piccaluga et al., 2015; Orvain et al., } \\
2020\end{array}$ \\
\hline $\begin{array}{l}\text { ZBP1 } \\
(\mathrm{DAl})\end{array}$ & $\begin{array}{l}\text { Z-dsDNA } \\
\text { or RNA }\end{array}$ & $\begin{array}{l}\text { Virus infection; cytosolic } \\
\text { self-DNA; endogenous RNA }\end{array}$ & $\begin{array}{l}\text { IFN1 expression; cell death; } \\
\text { NLRP3 activation }\end{array}$ & MSCs; intestinal stem cells & Wang et al., 2020; Zhao et al., 2020 \\
\hline AIM2 & dsDNA & $\begin{array}{l}\text { Virus infection; cytosolic } \\
\text { self-DNA }\end{array}$ & $\begin{array}{l}\text { AIM2 inflammasome complex } \\
\text { assembly; IL-18 and IL-1 } \beta \\
\text { activation; cell death }\end{array}$ & $\begin{array}{l}\text { Intestinal stem cells; epithelial } \\
\text { stem cells; MSCs }\end{array}$ & $\begin{array}{l}\text { Man et al., 2015; Yang et al., 2015; } \\
\text { Naik et al., } 2017\end{array}$ \\
\hline NLRP3 & dsDNA & $\begin{array}{l}\text { Virus infection; cytosolic } \\
\text { self-DNA }\end{array}$ & $\begin{array}{l}\text { NLRP3 inflammasome complex } \\
\text { assembly; IL-18 and IL-1 } \beta \\
\text { activation; cell death }\end{array}$ & HSCs; MSCs; CSCs & $\begin{array}{l}\text { Huang et al., 2017; Adamiak et al., } \\
\text { 2020; Ahn et al., } 2020\end{array}$ \\
\hline RLRs & dsRNA & $\begin{array}{l}\text { Virus infection; endogenous } \\
\text { dsRNA; ERV expression }\end{array}$ & IFN1 and ISGs expression & NSCs; MSCs; HSCs & $\begin{array}{l}\text { Yang et al., 2013; Lin et al., 2019; } \\
\text { Clapes et al., } 2021\end{array}$ \\
\hline Dicer & $\begin{array}{l}\text { dsRNA or } \\
\text { ncRNA }\end{array}$ & $\begin{array}{l}\text { Virus infection; endogenous } \\
\text { dsRNA; ERV expression; } \\
\text { miRNA }\end{array}$ & $\begin{array}{l}\text { dsRNA cleavage and IFN1 } \\
\text { repression }\end{array}$ & $\begin{array}{l}\text { Embryonic stem cells; NSCs; } \\
\text { CSCs; hair follicle stem cells; } \\
\text { intestinal stem cells }\end{array}$ & $\begin{array}{l}\text { Kawase-Koga et al., 2010; lliou } \\
\text { et al., 2014; Park et al., 2017; } \\
\text { Vishlaghi and Lisse, 2020; Gurung } \\
\text { et al., } 2021\end{array}$ \\
\hline
\end{tabular}


Recent studies have also shown a strong relation between specific types of stem cells and cytosolic DNA sensors (Liao et al., 2020). For example, proteins of the cGAS-STING pathway might be highly expressed in hematopoietic stem and progenitor cells (HSPCs) allowing a quick response to stress events and thus becoming critical components of HSPC-driven hematopoiesis (Qian et al., 2016; Liao et al., 2020). Hence, dysregulation of this pathway may lead to myeloid malignancies and inflammationrelated diseases such as cardiovascular and metabolic diseases (Liao et al., 2020). Furthermore, recent works showed that activation of STING enhances the formation of a stem cell-like memory phenotype in T cells with a potential beneficial effect for immunotherapy (Li et al., 2020). STING may also play a pivotal role in the differentiation of neuronal progenitor cells (NPCs) into neurons by sensing DNA damage during brain development (Zhang et al., 2020).

Z-DNA binding protein 1 (ZBP1), also known as DLM-1 and DAI (DNA-dependent activator of IFN-regulatory factors), is another potential cytoplasmic recognition receptor able to sense nucleic acids from endogenous and exogenous sources (Table 1). Its role as Z-DNA/Z-RNA sensor has been long questioned and further studies are required to elucidate its exact function in inflammation and cell death. However, it has been observed that its activation upon cytoplasmic DNA recognition is sufficient to induce the expression of IFN1 through the activation of IRF3 and IRF7, independently from STING, as well as to induce necroptosis and the NLRP3 inflammasome complex (Takaoka et al., 2007; Kuriakose and Kanneganti, 2018) (Figure 2). Importantly, an uncontrolled execution of necroptosis and the release of immunogenic molecules by dying cells may result in detrimental inflammatory responses further driving autoimmune and chronic diseases such as skin inflammation, pulmonary diseases, kidney fibrosis, cardiovascular diseases, and neurodegenerative disorders (Choi et al., 2019; Devos et al., 2020).

\section{Inflammasome Activation and Cytokine Release}

Activation of the inflammasomes, formed by innate immune system receptors and sensors (Guo et al., 2015), is another key event for the regulation and induction of inflammation. Upon sensing of PAMP and DAMP molecules inflammasomes are assembled by self-oligomerization into a caspase-1-activating scaffold leading to proinflammatory IL-1 family cleavage and bioactivation (Guo et al., 2015). Inflammasomes are mostly expressed by immune cells and the activation of caspase- 1 is not only linked to pro-inflammatory cytokine promotion, but it is also a defining feature of a peculiar type of cell death called pyroptosis. This type of immunogenic cell death is caused by the formation of pores into the cell membrane that are generated upon cleavage of gasdermin D (Liu et al., 2016). This leads to a rapid plasma-membrane rupture and consequent release of proinflammatory molecules into the extracellular environment (Bergsbaken et al., 2009) (Figure 2). IL-1 $\beta$ together with IL-18 are the main pro-inflammatory cytokines produced upon inflammasome activation and after being released they can activate a broad spectrum of immunological and inflammatory responses (Strowig et al., 2012; Dinarello, 2018).

Different types of inflammasomes have been identified and described in literature (Schroder and Tschopp, 2010) and among them NLRP3 and AIM2 inflammasomes are the ones that are mostly related to DNA damage and cytokine release (Inoue and Shinohara, 2013; Wei et al., 2019). NLRP3 is part of the NLR protein family (He et al., 2016) and can be activated upon recognition of viral components as well as cytosolic danger signals (Zhao and Zhao, 2020). In the activated form, NLRP3 inflammasome is a multi-protein complex, constituted by NLRP3, ASC and procaspase-1, that is able to bioactivate IL- $1 \beta$ and IL-18 upon caspase- 1 activation (Sharma and de Alba, 2021) (Figure 2). In particular, it has been observed that DNA damage in skin cells does not cause apoptosis but activation of a fibroblast-specific NLRP3 inflammasome and IL-1 $\beta$ secretion, which lead to defects in stem cell specification and consequent epithelial and dermal hyperplasia (Seldin and Macara, 2020). Similar results have been observed in human keratinocytes upon exposure to UV light. UV-induced DNA damage mediates an increase in NLRP3 gene expression and inflammatory cytokine production, such as IL- $1 \beta$, IL- 6 and $\mathrm{TNF} \alpha$, indicating that DNA damage induces the activation of NLRP3 inflammasome potentially leading to cutaneous tissue disorders (Hasegawa et al., 2016). Moreover, IL-1 $\beta$ and $\mathrm{TNF} \alpha$ have been shown to affect adipogenic and osteogenic potential of murine mesenchymal stem cells (MSCs) in vitro, which might correlate with collageninduced arthritis in vivo (Sullivan et al., 2014).

Like NLRP3, AIM2 inflammasome activation is also important for the recognition of cytosolic dsDNA (Table 1). Indeed, AIM2 is an HIN-200 protein family member able to activate caspase1 upon sensing of cytoplasmic DNA (Fernandes-Alnemri et al., 2009). Similarly to the NLRP3 inflammasome, interaction of AIM2 with ASC allows the activation of procaspase-1 leading to IL-1 $\beta$ and IL-18 activation and pyroptosis induction (Hornung et al., 2009; Sagulenko et al., 2013) (Figure 2). Interestingly, a recent study showed that AIM2 can also sense radiation-induced DNA damage into the nucleus of epithelial and bone marrow cells leading to AIM2 inflammasome assembly (Hu et al., 2016). As a consequence, AIM2 inflammasome can promote caspase1 activation, immunogenic cell death and release of mature cytokines into the surrounding environment (Hu et al., 2016). As mentioned previously, CSCs also strongly depend on their microenvironment and events, like pyroptosis, with the consequent release of IL-1 $\beta$ and IL-18 into the extracellular environment might potentially lead to stimulation of dormant CSCs, leading to increased tumor treatment resistance and metastases (Tulotta et al., 2019; Van Gorp and Lamkanfi, 2019). This further supports pharmacologic inhibition of IL-1 $\beta$ as a potential cancer treatment strategy (Tulotta et al., 2019).

\section{Role of RIG-1-Like Receptors in dsRNA Sensing}

The activation of nucleic acid sensors is not only limited to the recognition of cytosolic self-DNA but can also be induced by the presence of endogenous double-stranded RNA 
(dsRNA). Activation of retinoic acid-inducible gene 1 (RIG-1) like receptors (RLRs) can be triggered by both viral and host-derived RNAs leading to strong immune activation and inflammatory responses (Table 1) (Rehwinkel and Gack, 2020; Onomoto et al., 2021).

Several studies have shown a connection between the promotion of the IRF3-IFN1 axis and activation of RLRs in response to DNA damage. In particular, deregulation of both RIG-1 and MDA5 has been associated to autoimmune and inflammatory diseases induced by a STING-mediated IFN1 production (Ghosh et al., 2018; Onomoto et al., 2021).

Although why and how dsRNA is being released after DNA damage largely remains to be elucidated, recent studies showed an activation of latent endogenous retroviruses (ERVs) upon irradiation and DNA DSB formation. ERVs are originated from retroviruses that are thought to have infected early ancestor's germ cells millions of years ago and most of these ERVs are normally silent or suppressed (Gao et al., 2021). However, it has been observed that after stress events, such as ionizing radiationinduced DNA damage, there is an activation of these dormant genes with consequent formation and release of dsRNA and IFN1 expression through the activation of STING (Lee et al., 2020). The promotion of these ERVs upon DNA damage may enhance the activation of transcription factors leading to innate immunity activation and secretion of molecules with similar consequences as the ones observed upon dsDNA recognition and cytosolic DNA sensor activation (Figure 2).

Another protein involved in dsRNA sensing is the endoribonuclease Dicer (Table 1), this enzyme is usually required for the processing and maturation of miRNAs (a class of small ncRNAs important for the regulation of gene expression at the post-transcriptional level) (Kuehbacher et al., 2007). However, recent studies showed its essential role also in the recognition and clearance of dsRNA localized in both the cytoplasm and the nucleus (Much et al., 2016; Burger et al., 2017). In fact, its downregulation has been shown to correlate with dsRNA accumulation and consequent IFN1 production in vitro (White et al., 2014). Interestingly, Dicer and its isoform (aviD) (Poirier et al., 2021) have been shown to be upregulated in NSCs, embryonic stem cells and adult intestinal stem cells (Kawase-Koga et al., 2010; Park et al., 2017; Gurung et al., 2021), and knock down of aviD has been shown to be related to higher levels of stem cell apoptosis upon viral infection (Poirier et al., 2021). Moreover, a DNA damage-inducible phospho-switch of Dicer has been linked with accumulation of this protein into the nucleus and consequent dsRNA clearance and prevention of RLR activation (Burger et al., 2017). Although central in dsRNA clearance upon viral infection, it remains unknown whether Dicer and aviD might play a role in the modulation of DNA damage-induced IFN1 expression in both normal and cancer stem cells.

\section{Role of Mitochondrial DNA in Inflammation and Immunity}

Mitochondria are dynamic and essential organelles important for cellular bioenergetic maintenance, calcium metabolism and apoptotic processes (Detmer and Chan, 2007), and a proper function of this organelle is also important for stem cell selfrenewal and differentiation (Zhang $\mathrm{H}$. et al., 2018). Next to the DNA in the nucleus, also mitochondria contain several copies of their own circular DNA and changes in mitochondrial DNA (mtDNA) are often implicated in gene expression alterations, loss of tissue function, cancer and diseases (Singh et al., 2015; Castellani et al., 2020). DNA damage has been associated to mitochondrial dysfunction either via direct damage to the mtDNA or via depletion of nicotinamide adenine dinucleotide $(\mathrm{NAD}+)$ through activation of PARP1, a DDR protein that consumes $\mathrm{NAD}+$, causing an imbalance in energy levels (Schumacher et al., 2021). Other processes such as DNA damageassociated defects in mitophagy and mtDNA replication might also contribute to mitochondrial dysfunction (Fang et al., 2014).

Mitochondrial disfunction and the consequent mtDNA leakage into the cytoplasm have been related to inflammatory responses upon activation of DNA sensor molecules. Similar to cytosolic self-DNA, recognition of cytosolic mtDNA can trigger the induction of inflammatory pathways, such as cGAS and NOD-like receptors leading to STING activation, promotion of IFN $\beta$ expression, release of NF- $\kappa \mathrm{B}$-related cytokines release as well as increased transcription and activation of IL- $1 \beta$ and IL-18 (Dib et al., 2015; Mussil et al., 2019; Guo et al., 2020). As mentioned previously, the release of these pro-inflammatory cytokines into the stem cell microenvironment can strongly affect stem cell function and self-renewal. Additionally, mitochondria are a major source of ROS and mitochondrial dysfunction can lead to the release of ROS, which in turn further damages the mitochondria and their mtDNA reinforcing the associated inflammatory response. Interestingly, specific inhibition of mitochondrial ROS was shown to prevent the activation of the NLRP3 inflammasome (Chen et al., 2018).

Furthermore, DSBs of mtDNA upon genotoxic events have been associated with mitochondrial disfunction and consequent mitochondrial RNA (mtRNA) release thereby triggering RIG-1dependent pathways. Recognition of cytoplasmic mtRNA leads to IFN1 activation and ISG promotion in order to cope with the damaged mtDNA emphasizing the importance of mitochondrianucleus communication and immunity activation (Tigano et al., 2021). In conclusion, release and recognition of mtDNA upon DSBs can trigger similar immunostimulatory events as the ones observed upon recognition of cytoplasmic self-DNA suggesting that also mtDNA can potentially be implicated in stem cell functional defects and immunity activation. The specific role of mtDNA recognition in inflammation has been recently reviewed by Riley and Tait (2020) (Figure 2).

\section{IMMUNE CELL INFILTRATION IN THE STEM CELL MICROENVIRONMENT}

The immune system works as the main body's line of defense against pathogens, toxins and tumors while simultaneously being involved in other cellular processes such as tissue development, homeostasis, and repair. The immune response is traditionally classified into innate and adaptive (Vivier and Malissen, 2005). 
The innate immune cells, such as natural killer cells, mast cells and phagocytic cells, are activated by PAMPs and DAMPs and their non-specific response includes phagocytosis, cell locomotion, killing of pathogens or cells and cytokine production. On the other hand, the adaptive immune response is antigen specific and able to create a long-term immunological memory mediated by cells, like dendritic cells, specialized T cells and B cells (Netea et al., 2020). Interestingly, the innate immune response can be also mediated by stem cells such as HSCs. Indeed, it has been shown that HSCs can create an epigenetic memory in response to genotoxic stress or pathogens and that IFN $\gamma$ can specifically lead to proliferation and myeloid-biased progenitor differentiation during an innate immune response to infection (Aurora and Olson, 2014; Matatall et al., 2014).

As previously described pathways related to immune cell activation and DNA damage recognition are strongly interconnected and the release of immune modulators upon DNA damage responses can recruit and activate immune cells emulating pathogen infections or tissue injury. An uncontrolled infiltration of immune cells may severely compromise stem cell self-renewal capacity by affecting the local stem cell microenvironment leading to a loss in cellular homeostasis in healthy organs and tissues (Naik et al., 2018). Indeed, it has been observed that infiltration of macrophages can influence skeletal muscle regeneration by affecting the activity and recruitment of fibroadipogenic progenitor cells into the injury site (Low et al., 2017; Dort et al., 2019).

Macrophages are highly dynamic and essential innate immune cells implicated in tissue homeostasis and regeneration. Their activity is highly controlled by specific signals and their polarization toward a proinflammatory (M1) or antiinflammatory (M2) phenotype is strongly dependent on the presence of specific cytokines within the environment (BarcellosHoff et al., 2005). Pro-inflammatory macrophages are mostly induced my microbial elements as well as TLR ligands and cytokines such as IFNs and $\mathrm{TNF} \alpha$, while anti-inflammatory macrophages can be induced by cytokines like IL-4 and IL13 (Barcellos-Hoff et al., 2005; Viola et al., 2019). IRFs and $\mathrm{NF}-\kappa \mathrm{B}$ are the main transcription factors involved in cytokine and chemokine release and chronic activation of these pathways upon DNA damage can thereby influence the recruitment and functionality of unpolarized macrophages (Platanitis and Decker, 2018) (Figure 3, points 1-3).

Other immune regulatory cells, such as MSCs, are able to differentiate into a variety of cell types promoting repair and remodeling of tissues such as bone, cartilage, muscle, adipose and connective tissues (DiMarino et al., 2013; MacDonald and Barrett, 2020). MSCs foster the regeneration of these tissues by controlling immune cell activation, angiogenesis, and extracellular matrix deposition (DiMarino et al., 2013).

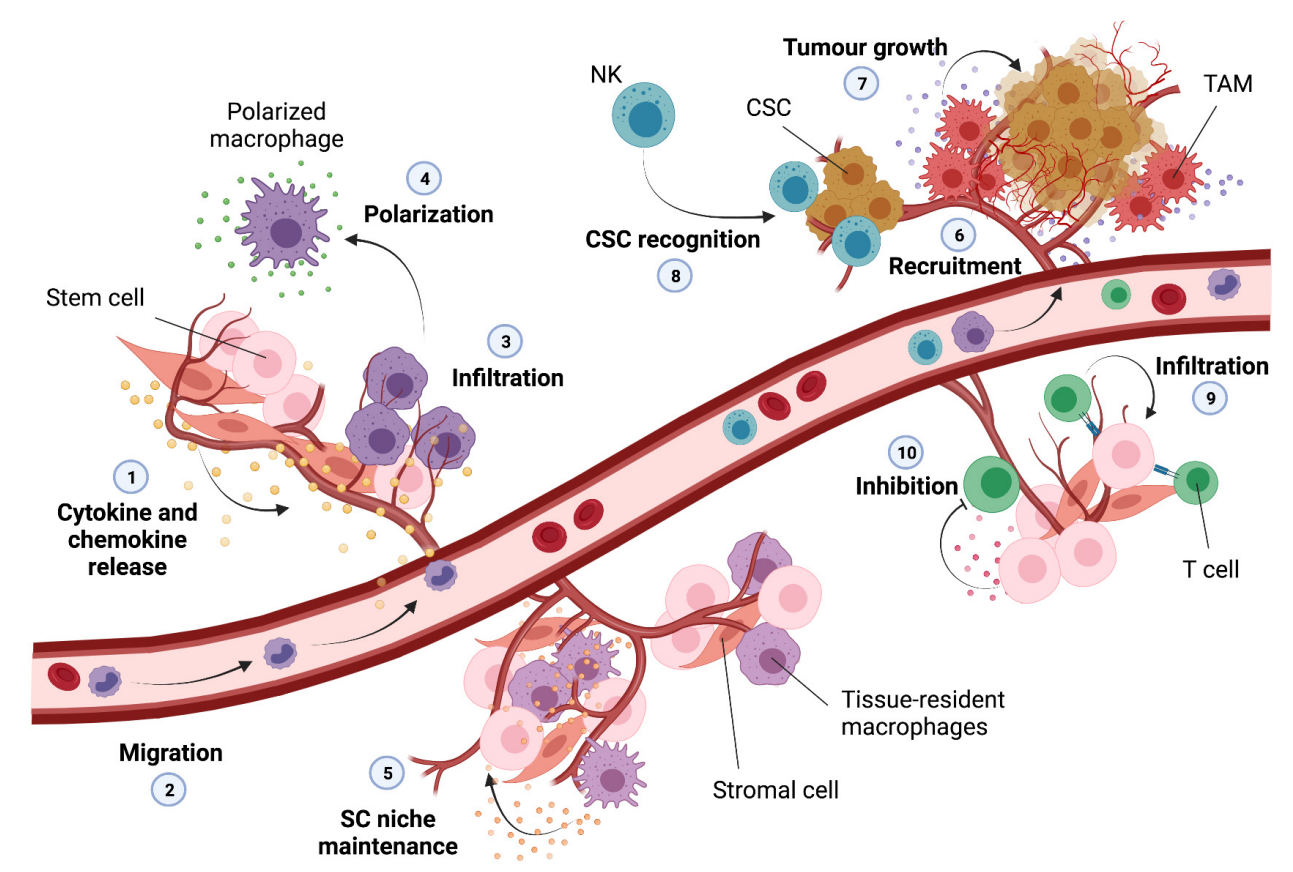

FIGURE 3 | Infiltration of immune cells into the normal stem cell and cancer stem cell niche. DNA damage can trigger the release of various cytokines and chemokines into the microenvironment (1); these can lead to migration and recruitment of macrophages (2) that exit the circulation and infiltrate into the tissue (3). The inflammatory microenvironment is then able to trigger the polarization of these macrophages (4) into M1 or M2 subtypes. Tissue-resident macrophages are normally present into the stem cell microenvironment, and they are important for the maintenance of the stem cell niche (5). The tumor microenvironment can lead to recruitment of various immune cells (6); tumor associated macrophages (TAM) can secrete inflammatory cytokines important for tumor growth and expansion (7); natural killer (NK) cells can potentially recognize and eliminate cancer stem cells (CSC) upon infiltration (8). T-cells can infiltrate into the normal stem cell niche (9) influencing stem cell proliferation and homeostasis; some types of stem cells are able to secrete molecules able to inhibit activation and differentiation of infiltrated T-cells (10). 
Recent studies showed that inflammatory cytokines produced by polarized macrophages (Figure 3, point 4) can influence migration and differentiation of human MSCs toward an osteoblastic lineage essential for effective bone tissue regeneration and spinal cord repair (Maldonado-Lasunción et al., 2018; Vallés et al., 2020). Furthermore, it has been shown that MSCs can maintain tissue homeostasis upon injury by inhibiting macrophage activity and T-cell mediated immune responses and thus preserving the activity of corneal epithelial precursor cells (Ko et al., 2020).

Macrophage's polarization has been suggested to influence not only MSCs but also HSC self-renewal capacity and quiescence status. In fact, macrophages are essential regulators of HSC pool size and mobilization, and the cytokines produced by proinflammatory macrophages can directly affect haematopoiesis by acting on the HSC niche and function (McCabe and MacNamara, 2016; Seyfried et al., 2020). It has been described that in physiological conditions tissue resident-macrophages positively contribute to bone marrow homeostasis by promoting HSC niche maintenance and activity. Indeed, these tissue-resident immune cells can produce matrix metalloproteinases in order to degrade the matrix that surrounds HSCs leading to HSC escape into the circulation (Winkler et al., 2010). However, another study showed that resident macrophages are also important for the retention of HSCs in the spleen through the expression of adhesion molecules (Figure 3, point 5). Thus, this demonstrates that elimination of tissue resident macrophages can cause HSC escape into the circulation influencing extramedullary hematopoiesis (Dutta et al., 2015).

The dual proinflammatory and anti-inflammatory feature that macrophages can acquire upon infiltration plays a pivotal role in tissue homeostasis and stem cell function. This seems to be particularly important also for the CSC niche and tumor progression. Macrophage infiltration has been recently associated with many types of tumors and their presence in the tumor environment together with their paracrine signaling have been linked to glioblastoma growth and spread of the CSC phenotype (Shi et al., 2017). Recent works have observed a correlation between the presence of tumor associated macrophages (TAMs) and CSC niche modification and expansion. TAMs are crucial components of the tumor microenvironment, able to exert pro-tumor features through the activation of specific signaling pathways and secretion of a broad range of inflammatory cytokines. For instance, it has been observed that TAMs are able to physically interact with CSCs leading to induction of $\mathrm{NF}-\kappa \mathrm{B}$ and release of cytokines for the sustainment of the CSC phenotype ( $\mathrm{Lu}$ et al., 2014). Furthermore, TAMs are also able to promote CSC-like properties through the secretion of higher levels of TGF $\beta 1$ compared to other type of macrophages (Fan et al., 2014). Lastly, the presence of TAMs has been positively associated with CSC density in human tumors and the consequent release of pro-inflammatory cytokines has been correlated with an increase of CSC-like cells and invasiveness (Fan et al., 2014) (Figure 3, point 6-7).

Unlike macrophages, natural killer (NK) cells possess abilities to infiltrate and selectively kill CSCs. They are major effectors of innate immunity and therefore able to display a strong cytolytic activity against many tumors or virus-infected cells. Although the role of NK cells in cancer surveillance remains still under debate, recent in vivo and in vitro studies suggested that NK cells may be able to specifically detect CSCs through the recognition of surface markers leading to a possible decrease in tumor malignity (Tallerico et al., 2017). Furthermore, reduced function of NK cells has been associated with increased risk of developing tumors together with an increased risk in tumor-related mortality (Luna et al., 2017) (Figure 3, point 8).

$\mathrm{T}$ cells coordinate multiple adaptive immune responses and are responsible for the recognition of pathogens, antigens and tumors. They originate from bone marrow progenitor cells and upon maturation in the thymus migrate to the periphery of the body in order to exert their patrolling functions. Upon antigen encounter, $\mathrm{T}$ cells are able to differentiate into effector cells, a key event for the elimination of pathogens through the production of several cytokines and cytotoxic mediators (Kumar et al., 2018; Goswami and Awasthi, 2020). It has been shown that MSCs can influence $\mathrm{T}$ cell proliferation and differentiation in vitro through the secretion of a number of soluble factors (Duffy et al., 2011). Galectin-1 in particular is highly expressed by MSCs and able to directly inhibit $\mathrm{T}$ cell activation. Indeed, knockdown of this protein in vitro has been shown to partially rescue proliferation of both killer and helper T lymphocytes (Gieseke et al., 2010). T cells can differentiate into different subsets of cells; however, dysregulation of this process can lead to immunological deficiencies and autoimmune diseases. For example, it has been observed that NPCs are able to selectively inhibit differentiation of pathogenic $\mathrm{T}$ cells through the expression of leukaemia inhibitory factor (LIF) receptors providing potential new insights into multiple sclerosis (Cao et al., 2011). On a separate study, using scRNA sequencing $\mathrm{T}$ cells have been shown to infiltrate the adult sub-ventricular zone NSC niche during aging. T cells in old brains secrete IFN $\gamma$ which promotes a decrease in proliferation of NSCs in both co-culture experiments and in vivo (Dulken et al., 2019) (Figure 3, point 9).

Furthermore, MSCs are also able to indirectly modulate $\mathrm{T}$ cell activity by affecting maturation and differentiation of antigen presenting cells, such as dendritic cells, important for antigen processing and presentation (Jiang et al., 2005). While neoantigen presentation has been mostly studied in cancer (stem) cells with a focus on $\mathrm{T}$ cells and the expression of major histocompatibility complex I (MHC-I) after radiationor chemotherapy-induced DNA damage in connection with an increased mutational load and subclonal neoantigen generation (McLaughlin et al., 2020), little is known about DNA damage and neoantigen presentation in normal tissue-specific stem cells and their microenvironment (Figure 3, point 10).

\section{THE DUAL ROLE OF CELLULAR SENESCENCE IN STEM CELL FUNCTION}

Cellular senescence is described as an irreversible state of growth arrest triggered by a number of oncogenic events, such as telomere shortening, chromatin perturbation, replication stress, DNA damage and chronic exposure to anti-proliferative 
cytokines like IFN $\beta$. Unlike quiescence, the senescence state is permanent and cannot be reversed by known physiological stimuli (Campisi and D’Adda Di Fagagna, 2007; Collado et al., 2007). Senescent cells undergo morphological changes accompanying by apoptosis resistance and an altered gene expression pattern that leads to deep metabolic reprogramming and secretion of a wide range of soluble and insoluble factors collectively named senescence-associated secretory phenotype (SASP) (Herranz and Gil, 2018). Furthermore, senescence is associated with persistent DDR activation often correlated with high expression of cell-cycle inhibitors, such as p21 (also termed CDKN1a) and p16 (also termed CDKN2a) (Campisi and D'Adda Di Fagagna, 2007; Faget et al., 2019).

The SASP is a common feature of senescent cells, able to induce paracrine signaling through the secretion of factors including inflammatory cytokines and chemokines. Importantly, it has been observed that there is not a singular SASP phenotype and its composition can change depending on the senescence-inducing triggering factor and cell type (Gonzalez-Meljem et al., 2018). Recent studies have demonstrated that a prolonged DDR activation (Fumagalli et al., 2014) as well as activation of previously mentioned DNA damage-related mechanisms, such as cGAS/STING (Yang et al., 2017), inflammasomes (Yin et al., 2017) and mitochondrial stress pathways (Passos et al., 2007), are able to induce autocrine and paracrine senescence of neighboring cells through the secretion of SASP factors. The promotion of these pathways seems to converge on $\mathrm{C} / \mathrm{EBPB}$ and NF- $\mathrm{B}$ activation, responsible for the direct regulation of inflammatory cytokine expression and release, in particular IL-8, IL-6 and IL- $1 \alpha$ (Herranz and Gil, 2018). IL-1 signaling has been linked to in vivo paracrine senescence upon activation of the inflammasome complex (Acosta et al., 2013), while IL-6 and IL-8 are specific interleukins able to act in a paracrine manner to promote senescence development, and their depletion has been shown to prevent senescence entry in vitro (Kuilman et al., 2008). Furthermore, STING activation and a sustained IFN $\beta$ signaling also cause senescence. Indeed, it has been shown that acute IFN $\beta$ stimulation can reversibly arrest cell growth while its chronic stimulation leads to p53-dependent cell cycle arrest and subsequent senescence (Moiseeva et al., 2006).

Although stem cells are able to divide and renew over a long period of time, they are also susceptible to cell cycle arrest and senescence upon exposure to genotoxic stress thereby affecting tissue regeneration and homeostasis (Vitale et al., 2017). A clear example is given by radiation induced-DNA damage, which can promote senescence in different types of stem cells (Chen Z. et al., 2019). In a recent study it has been observed that irradiation induces senescence of bone marrow-derived mesenchymal stem cells (BMSCs), which can be associated with decline in bone formation, a typical side effect of anticancer therapies. Importantly, the secretion of SASP components by senescent BMSCs worsens bone marrow remodeling by inducing osteogenic differentiation dysfunction via paracrine signaling. SASP can therefore be a potential target to ameliorate radiationinduced bone loss (Bai et al., 2020). Although quiescent HSCs are relatively radioresistant, they can be affected by radiationinduced ROS production (Shao et al., 2014; McBride and Schaue, 2020). Indeed, HSCs appear to be quite sensitive to oxidative stress generated upon irradiation or through the activation of proinflammatory pathways (McBride and Schaue, 2020). These events can cause HSCs to undergo premature senescence leading to long-term bone marrow suppression and decrease repopulation capacity (Shao et al., 2014). Cellular senescence has also been identified in NPCs of primary progressive multiple sclerosis (MS)-derived tissue linking DNA damage to remyelination failure and thus offering potential new treatments against MS (Nicaise et al., 2019). In salivary glands irradiation is able to induce accumulation of senescent cells in or near the salivary gland stem and progenitor cell (SGSC) niche both in vitro and in vivo leading to tissue-specific functional impairment. Selective elimination of senescent cells was shown to improve the self-renewal of SGSCs and to partially rescue salivary secretion activity (Peng et al., 2020). Furthermore, SASP release has been shown to play a pivotal role in salivary gland homeostasis and function upon radiation-induced senescence (Marmary et al., 2016). Sustained expression of IL-6 in particular is known to be essential for both induction of senescence and tissue hypofunction. However, exposure to this cytokine prior irradiation has been shown to enhance DNA repair preventing senescence and salivary gland dysfunction (Marmary et al., 2016). Senescence and SASP promotion can also cause perturbation of the intestinal stem cell niche contributing to potential gastrointestinal disorders, inflammation and carcinogenesis upon heavy ion irradiation and DNA damage (Kumar et al., 2019).

In contrast to normal tissue-specific stem cells, due to its pro-inflammatory features, cellular senescence plays a pivotal role in cancer promotion and stemness. SASP can create an immunosuppressive environment driving tumorigenesis, tumor progression and metastasis (Faget et al., 2019). In multiple myeloma, the release of chemokines, like IP-10 and RANTES, by senescent cells was shown to favor the emergence and maintenance of cancer stem-like cells (Cahu et al., 2012). In CSCs, a gain of stem celllike features can severely impact tumor progression and aggressiveness. A recent study showed that chemotherapyinduced senescence can lead to a significant upregulation of stem-cell like markers, such as Kit and Sca1, in senescent cells compared to non-senescent cells thereby leading to a much more aggressive tumour phenotype (Milanovic et al., 2018).

Although senescence and SASP are generally associated with aging-related diseases and tumorigenesis, recent studies have also brought to light a positive impact of senescence and SASP in the regeneration and cell reprogramming of some tissues. In acute and chronic muscle injury, cellular plasticity and skeletal muscle reprogramming were shown to be promoted by muscledamage-induced senescence and SASP release (Chiche et al., 2017). Furthermore, it has been observed that transient exposure to SASP factors promotes cell plasticity, tissue regeneration and stemness while chronic SASP exposure counteracts the regeneration stimuli by inducing cell cycle arrest. Specifically, Ritschka et al. (2017) showed that incubation of primary mouse 
keratinocytes with conditioned medium from oncogene-induced senescent cells during a short-term period of 2 days led to increased stem cell features and that transplantation of these cells generated more hair follicles compared to untreated cells. However, upon a prolonged exposure to the same SASP both cell-intrinsic and paracrine senescence was observed (Ritschka et al., 2017). Similar findings have been reported by Mosteiro et al. (2018), whose work showed that senescence is important for in vivo tissue reprogramming mediated by OCT4, SOX2, KLF4, and MYC (OSKM), four transcription factors used to reprogram somatic cells into iPSCs (Cai et al., 2015; Cevallos et al., 2020). Following this approach, the authors found that paracrine secretion of IL- 6 and other soluble factors is essential for the reinforcement of cellular senescence and regeneration upon damage in vivo (Mosteiro et al., 2018). This has been recently observed also in fibro-adipogenic progenitor cells highlighting the importance of SASP and senescence in tissue remodeling and plasticity (Saito et al., 2020). Senescence is clearly a powerful mechanism important not only for cell cycle arrest but also for the induction of a state of regenerative inflammation that enhances tissue repair and function upon DNA damage.

\section{CONCLUDING REMARKS}

DNA damage profoundly affects the inflammatory microenvironment where stem cells reside, which can have detrimental consequences for their maintenance and long-term function. Indeed, it has been shown that DNA damage-induced immunostimulatory events can lead to tissue-specific stem cell exhaustion leading to degenerative conditions. Conversely, the release of specific cytokines can also positively impact tissuespecific stem cell plasticity and regeneration of damaged tissues in addition to enhance CSC activity leading to tumor progression.

This review provides an overview of the main biological mechanisms linked to changes in the stem cell microenvironment and activation of immune processes upon DNA damage induction. Although recent findings have brought to light new insights into these DNA damage-related inflammatory events, some questions remain unanswered. For instance, it is still not clear how to exploit the production of inflammatory cytokines in order to promote on one side immunostimulatory responses against the tumor and on the other side immunosuppressive responses against aging-related degenerative conditions. Especially since the activation of DNA and RNA sensors might change depending on the specific stimulus and cell type. For example, it has been shown that cytosolic DNA in keratinocytes of psoriatic lesions or exposure of hematopoietic cells to ionizing radiation can both trigger the activation of the AIM2 inflammasome (Dombrowski et al., 2011). However, exposure of keratinocytes to UVB has been shown to induce NLRP3 and cGAS activation with consequent production of a broad spectrum of cytokines including IL-1, IL-6, TNF $\alpha$, and IFN1 (Hasegawa et al., 2016; Li et al., 2021). These studies exemplified how different stimuli can trigger the activation of different sensors within the same cell type. Whether such observations might also apply to adult stem cells and their self-renewal capacity leading to organ-/tissue-specific outcomes remains to be elucidated.

DNA damage-induced senescence plays a pivotal role in cell cycle arrest and can be used as a barrier against tumor expansion; however, due to the accompanying SASP, it is also responsible for loss of tissue function, aging-related diseases and tumor progression. Therefore, further studies are required to understand how to properly modulate the exposure to SASP factors toward the promotion of a regenerative state and against detrimental effects, such as paracrine senescence of neighboring cells and chronic inflammation. Furthermore, it would be interesting to explore how different types of DNA damage can influence senescence and its SAPS phenotype in different adult stem cells. It has been shown that the SASP associated with radiation-induced DNA damage can differ from SASP induced by other stress factors, such as mitochondrial dysfunction (Wiley et al., 2016; Aratani et al., 2018). Moreover, p53 plays a central role in the DDR and its activity is essential for the prevention of cancer development by promoting cell death and senescence (Mijit et al., 2020). However, it has been shown that in some types of adult stem cells, such as hair follicle bulge stem cells and HSCs, reduced p53 activation upon irradiation mediates resistance to apoptosis or senescence (Sotiropoulou et al., 2010; Insinga et al., 2013) indicating that DDR proteins can actually trigger distinct responses in different types of stem and progenitor cells (Lee et al., 2013).

Further understanding of DNA damage immunomodulatory mechanisms, cell- and stimulus-specific variability might unravel novel strategies to regulate the stem cell microenvironment. Recently developed 3D in vitro models, such as organoids and organs-on-a-chip (OOC), represent innovative strategies to address these questions by closely resembling the normal and cancer stem cell microenvironment. Furthermore, organoid co-culture systems and assembloids, organoids generated by incorporating multiple cell types or by fusing organoids of different identities (Vogt, 2021), can be used to study the interaction between immune cells and normal or cancer stem cells upon genotoxic stress. For instance, OOC allow to mimic the combined response to several stimuli and environmental changes by using multiple cell types/stimuli in different chambers (Wu et al., 2020; Almela et al., 2021). These advanced 3D in vitro models together with 3D bioprinting techniques, which can reproduce complex tissue structures by using a combination of multicomponent bioinks and cell types (Almela et al., 2021), allow to generate a similar organizational complexity to in vivo tissues/organs with the ability to regulate key parameters, such as tissue interactions, concentration gradients and cell patterning (Wu et al., 2020; Almela et al., 2021).

As mentioned in this review, genotoxic stress can affect the stem cell microenvironment leading to stem cell exhaustion, likely through a combination of a decline in cell number and functional capacity, with the emergence of aging-related pathologies (Schumacher et al., 2021). On the other hand, due to their self-renewal properties, CSCs are also affected by DNA damage and the associated inflammatory microenvironment, which can worsen tumor control and treatment efficacy. Understanding the mechanistic links between stem cell 
properties and microenvironmental changes initiated upon DNA damage will be critical to counteract the functional decline of adult stem cells in aging-related diseases and effectively diminish CSC activity and expansion.

\section{AUTHOR CONTRIBUTIONS}

DC, RC, and LB wrote the manuscript. DC and LB designed the figures. All authors contributed to the article and approved the submitted version.

\section{REFERENCES}

Ablasser, A., and Chen, Z. J. (2019). CGAS in action: expanding roles in immunity and inflammation. Science 363:eaat8657. doi: 10.1126/science.aat8657

Acosta, J. C., Banito, A., Wuestefeld, T., Georgilis, A., Janich, P., Morton, J. P., et al. (2013). A complex secretory program orchestrated by the inflammasome controls paracrine senescence. Nat. Cell Biol. 15, 978-990. doi: 10.1038/ ncb2784

Adamiak, M., Abdel-Latif, A., Bujko, K., Thapa, A., Anusz, K., Tracz, M., et al. (2020). Nlrp3 inflammasome signaling regulates the homing and engraftment of hematopoietic stem cells (HSPCs) by enhancing incorporation of CXCR4 receptor into membrane lipid rafts. Stem Cell Rev. Rep. 165, 954-967. doi: 10.1007/S12015-020-10005-W

Ahn, J.-S., Seo, Y., Oh, S.-J., Yang, J. W., Shin, Y. Y., Lee, B.-C., et al. (2020). The activation of NLRP3 inflammasome potentiates the immunomodulatory abilities of mesenchymal stem cells in a murine colitis model. BMB Rep. 53, 329-334. doi: 10.5483/BMBREP.2020.53.6.065

Almela, T., Tayebi, L., and Moharamzadeh, K. (2021). 3D bioprinting for in vitro models of oral cancer: toward development and validation. Bioprinting 22:e00132. doi: 10.1016/J.BPRINT.2021.E00132

Almine, J. F., O'Hare, C. A. J., Dunphy, G., Haga, I. R., Naik, R. J., Atrih, A., et al. (2017). IFI16 and cGAS cooperate in the activation of STING during DNA sensing in human keratinocytes. Nat. Commun. 8:14392. doi: 10.1038/ ncomms 14392

Aratani, S., Tagawa, M., Nagasaka, S., Sakai, Y., Shimizu, A., and Tsuruoka, S. (2018). Radiation-induced premature cellular senescence involved in glomerular diseases in rats. Sci. Rep. 8:16812. doi: 10.1038/s41598-01834893-8

Aurora, A. B., and Olson, E. N. (2014). Immune modulation of stem cells and regeneration. Cell Stem Cell 15, 14-25. doi: 10.1016/j.stem.2014.06.009

Bai, J., Wang, Y., Wang, J., Zhai, J., He, F., and Zhu, G. (2020). Irradiation-induced senescence of bone marrow mesenchymal stem cells aggravates osteogenic differentiation dysfunction via paracrine signaling. Am. J. Physiol. Cell Physiol. 318, C1005-C1017. doi: 10.1152/ajpcell.00520.2019

Barazzuol, L., Ju, L., and Jeggo, P. A. (2017). A coordinated DNA damage response promotes adult quiescent neural stem cell activation. PLoS Biol. 15:e2001264. doi: 10.1371/JOURNAL.PBIO.2001264

Barcellos-Hoff, M. H., Park, C., and Wright, E. G. (2005). Radiation and the microenvironment - tumorigenesis and therapy. Nat. Rev. Cancer 5, 867-875. doi: $10.1038 / \mathrm{nrcl} 135$

Behrens, A., Van Deursen, J. M., Rudolph, K. L., and Schumacher, B. (2014). Impact of genomic damage and ageing on stem cell function. Nat. Cell Biol. 16, 201-207. doi: $10.1038 /$ ncb2928

Bergsbaken, T., Fink, S. L., and Cookson, B. T. (2009). Pyroptosis: host cell death and inflammation. Nat. Rev. Microbiol. 7, 99-109. doi: 10.1038/nrmicro2070

Biechonski, S., Yassin, M., and Milyavsky, M. (2017). DNA-damage response in hematopoietic stem cells: an evolutionary trade-off between blood regeneration and leukemia suppression. Carcinogenesis 38, 367-377. doi: 10.1093/CARCIN/ BGX002

Blanpain, C., and Simons, B. D. (2013). Unravelling stem cell dynamics by lineage tracing. Nat. Rev. Mol. Cell Biol. 14, 489-502. doi: 10.1038/nrm3625

Burger, K., Schlackow, M., Potts, M., Hester, S., Mohammed, S., and Gullerova, M. (2017). Nuclear phosphorylated Dicer processes double-stranded RNA in

\section{FUNDING}

RC received funding from Dutch Cancer Society (KWF) (Consortium grant 12092). LB received funding from Dutch Cancer Society (KWF) (Young Investigator grant 11148).

\section{ACKNOWLEDGMENTS}

Figures were created with biorender.com.

response to DNA damage. J. Cell Biol. 216, 2373-2389. doi: 10.1083/JCB. 201612131

Cahu, J., Bustany, S., and Sola, B. (2012). Senescence-associated secretory phenotype favors the emergence of cancer stem-like cells. Cell Death Dis. 3:446. doi: $10.1038 /$ cddis.2012.183

Cai, Y., Dai, X., Zhang, Q., and Dai, Z. (2015). Gene expression of OCT4, SOX2, KLF4 and MYC (OSKM) induced pluripotent stem cells: identification for potential mechanisms. Diagn. Pathol. 10:35. doi: 10.1186/S13000-015-0263-7

Campisi, J., and D'Adda Di Fagagna, F. (2007). Cellular senescence: when bad things happen to good cells. Nat. Rev. Mol. Cell Biol. 8, 729-740. doi: 10.1038/ nrm2233

Cao, W., Yang, Y., Wang, Z., Liu, A., Fang, L., Wu, F., et al. (2011). Leukemia inhibitory factor inhibits $\mathrm{T}$ helper 17 cell differentiation and confers treatment effects of neural progenitor cell therapy in autoimmune disease. Immunity 35, 273-284. doi: 10.1016/j.immuni.2011.06.011

Castellani, C. A., Longchamps, R. J., Sun, J., Guallar, E., and Arking, D. E. (2020). Thinking outside the nucleus: mitochondrial DNA copy number in health and disease. Mitochondrion 53, 214-223. doi: 10.1016/j.mito.2020.06.004

Cevallos, R. R., Edwards, Y. J. K., Parant, J. M., Yoder, B. K., and Hu, K. (2020). Human transcription factors responsive to initial reprogramming predominantly undergo legitimate reprogramming during fibroblast conversion to iPSCs. Sci. Rep. 10:19710. doi: 10.1038/s41598-020-76705-y

Chaudhuri, J., Bains, Y., Guha, S., Kahn, A., Hall, D., Bose, N., et al. (2018). The role of advanced glycation end products in aging and metabolic diseases: bridging association and causality. Cell Metab. 28:337. doi: 10.1016/J.CMET.2018. 08.014

Chen, M., Reed, R. R., and Lane, A. P. (2019). Chronic inflammation directs an olfactory stem cell functional switch from neuroregeneration to immune defense. Cell Stem Cell 25, 501-513.e5. doi: 10.1016/j.stem.2019.08.011

Chen, Y., Zhou, Z., and Min, W. (2018). Mitochondria, oxidative stress and innate immunity. Front. Physiol. 9:1487. doi: 10.3389/FPHYS.2018.01487

Chen, Z., Cao, K., Xia, Y., Li, Y., Hou, Y., Wang, L., et al. (2019). Cellular senescence in ionizing radiation (Review). Oncol. Rep. 42, 883-894. doi: 10.3892/or.2019. 7209

Chiche, A., Le Roux, I., von Joest, M., Sakai, H., Aguín, S. B., Cazin, C., et al. (2017). Injury-induced senescence enables in vivo reprogramming in skeletal muscle. Cell Stem Cell 20, 407-414.e4. doi: 10.1016/j.stem.2016.11.020

Choi, M. E., Price, D. R., Ryter, S. W., and Choi, A. M. K. (2019). Necroptosis: a crucial pathogenic mediator of human disease. JCI Insight 4:e128834. doi: 10.1172/jci.insight.128834

Clapes, T., Polyzou, A., Prater, P., Morales-Hernández, A., Galvao Ferrarini, M., Kehrer, N., et al. (2021). Chemotherapy-induced transposable elements activate MDA5 to enhance haematopoietic regeneration. Nat. Cell Biol. 23, 704-717. doi: 10.1038/s41556-021-00707-9

Collado, M., Blasco, M. A., and Serrano, M. (2007). Cellular senescence in cancer and aging. Cell 130, 223-233. doi: 10.1016/j.cell.2007.07.003

Coppes, R. P., and Dubrovska, A. (2017). Targeting stem cells in radiation oncology. Clin. Oncol. 29, 329-334. doi: 10.1016/j.clon.2017.03.005

Crane, G. M., Jeffery, E., and Morrison, S. J. (2017). Adult haematopoietic stem cell niches. Nat. Rev. Immunol. 17, 573-590. doi: 10.1038/nri.2017.53

Crasta, K., Ganem, N. J., Dagher, R., Lantermann, A. B., Ivanova, E. V., Pan, Y., et al. (2012). DNA breaks and chromosome pulverization from errors in mitosis. Nature 482, 53-58. doi: 10.1038/nature10802 
Crop, M. J., Baan, C. C., Korevaar, S. S., IJzermans, J. N. M., Pescatori, M., Stubbs, A. P., et al. (2010). Inflammatory conditions affect gene expression and function of human adipose tissue-derived mesenchymal stem cells. Clin. Exp. Immunol. 162, 474-486. doi: 10.1111/j.1365-2249.2010.04256.x

Detmer, S. A., and Chan, D. C. (2007). Functions and dysfunctions of mitochondrial dynamics. Nat. Rev. Mol. Cell Biol. 8, 870-879. doi: 10.1038/ nrm 2275

Devos, M., Tanghe, G., Gilbert, B., Dierick, E., Verheirstraeten, M., Nemegeer, J., et al. (2020). Sensing of endogenous nucleic acids by ZBP1 induces keratinocyte necroptosis and skin inflammation. J. Exp. Med. 217:e20191913. doi: 10.1084/ jem.20191913

Dib, B., Lin, H., Maidana, D. E., Tian, B., Miller, J. B., Bouzika, P., et al. (2015). Mitochondrial DNA has a pro-inflammatory role in AMD. Biochim. Biophys. Acta Mol. Cell Res. 1853, 2897-2906. doi: 10.1016/j.bbamcr.2015.08.012

DiMarino, A. M., Caplan, A. I., and Bonfield, T. L. (2013). Mesenchymal stem cells in tissue repair. Front. Immunol. 4:201. doi: 10.3389/fimmu.2013.00201

Dinarello, C. A. (2018). Overview of the IL-1 family in innate inflammation and acquired immunity. Immunol. Rev. 281, 8-27. doi: 10.1111/imr.12621

Doherty, M. R., Cheon, H., Junk, D. J., Vinayak, S., Varadan, V., Telli, M. L., et al. (2017). Interferon-beta represses cancer stem cell properties in triplenegative breast cancer. Proc. Natl. Acad. Sci. U.S.A. 114, 13792-13797. doi: 10.1073/pnas.1713728114

Dombrowski, Y., Peric, M., Koglin, S., Kammerbauer, C., Göß, C., Anz, D., et al. (2011). Cytosolic DNA triggers inflammasome activation in keratinocytes in psoriatic lesions. Sci. Transl. Med. 3:82ra38. doi: 10.1126/SCITRANSLMED. 3002001

Dort, J., Fabre, P., Molina, T., and Dumont, N. A. (2019). Macrophages are key regulators of stem cells during skeletal muscle regeneration and diseases. Stem Cells Int. 2019, 1-20. doi: 10.1155/2019/4761427

Duffy, M. M., Ritter, T., Ceredig, R., and Griffin, M. D. (2011). Mesenchymal stem cell effects on T-cell effector pathways. Stem Cell Res. Ther. 2:34. doi: $10.1186 /$ scrt75

Dulken, B. W., Buckley, M. T., Navarro Negredo, P., Saligrama, N., Cayrol, R., Leeman, D. S., et al. (2019). Single-cell analysis reveals T cell infiltration in old neurogenic niches. Nature 571, 205-210. doi: 10.1038/s41586-019-1362-5

Dunphy, G., Flannery, S. M., Almine, J. F., Connolly, D. J., Paulus, C., Jønsson, K. L., et al. (2018). Non-canonical activation of the DNA sensing adaptor STING by ATM and IFI16 Mediates NF- $\kappa$ B signaling after nuclear DNA damage. Mol. Cell 71, 745-760.e5. doi: 10.1016/j.molcel.2018.07.034

Dupont, S., Morsut, L., Aragona, M., Enzo, E., Giulitti, S., Cordenonsi, M., et al. (2011). Role of YAP/TAZ in mechanotransduction. Nature 474, 179-184. doi: 10.1038 /nature 10137

Dutta, P., Hoyer, F. F., Grigoryeva, L. S., Sager, H. B., Leuschner, F., Courties, G., et al. (2015). Macrophages retain hematopoietic stem cells in the spleen via VCAM-1. J. Exp. Med. 212, 497-512. doi: 10.1084/jem.20141642

Faget, D. V., Ren, Q., and Stewart, S. A. (2019). Unmasking senescence: contextdependent effects of SASP in cancer. Nat. Rev. Cancer 19, 439-453. doi: 10.1038/ s41568-019-0156-2

Fan, Q. M., Jing, Y. Y., Yu, G. F., Kou, X. R., Ye, F., Gao, L., et al. (2014). Tumor-associated macrophages promote cancer stem cell-like properties via transforming growth factor-betal-induced epithelial-mesenchymal transition in hepatocellular carcinoma. Cancer Lett. 352, 160-168. doi: 10.1016/j.canlet. 2014.05.008

Fang, E., Scheibye-Knudsen, M., Brace, L., Kassahun, H., SenGupta, T., Nilsen, H., et al. (2014). Defective mitophagy in XPA via PARP-1 hyperactivation and NAD(+)/SIRT1 reduction. Cell 157, 882-896. doi: 10.1016/J.CELL.2014.03.026

Fernandes-Alnemri, T., Yu, J. W., Datta, P., Wu, J., and Alnemri, E. S. (2009). AIM2 activates the inflammasome and cell death in response to cytoplasmic DNA. Nature 458, 509-513. doi: 10.1038/nature07710

Flach, J., Bakker, S. T., Mohrin, M., Conroy, P. C., Pietras, E. M., Reynaud, D., et al. (2014). Replication stress is a potent driver of functional decline in ageing haematopoietic stem cells. Nature 512, 198-202. doi: 10.1038/nature13619

Foell, D., Wittkowski, H., and Roth, J. (2007). Mechanisms of disease: a "DAMP" view of inflammatory arthritis. Nat. Clin. Pract. Rheumatol. 3, 382-390. doi: 10.1038/ncprheum0531

Fumagalli, M., Rossiello, F., Mondello, C., and D’Adda Di Fagagna, F. (2014). Stable cellular senescence is associated with persistent DDR activation. PLoS One 9:110969. doi: 10.1371/journal.pone.0110969
Gao, Y., Yu, X. F., and Chen, T. (2021). Human endogenous retroviruses in cancer: expression, regulation and function (Review). Oncol. Lett. 21:121. doi: 10.3892/ ol.2020.12382

Gasteiger, G., D’osualdo, A., Schubert, D. A., Weber, A., Bruscia, E. M., and Hartl, D. (2017). Cellular innate immunity: an old game with new players. J. Innate Immun. 9, 111-125. doi: 10.1159/000453397

Ghosh, R., Roy, S., and Franco, S. (2018). PARP1 depletion induces RIG-Idependent signaling in human cancer cells. PLoS One 13:e0194611. doi: 10. 1371/journal.pone.0194611

Gieseke, F., Böhringer, J., Bussolari, R., Dominici, M., Handgretinger, R., and Müller, I. (2010). Human multipotent mesenchymal stromal cells use galectin1 to inhibit immune effector cells. Blood 116, 3770-3779. doi: 10.1182/blood2010-02-270777

Gong, T., Liu, L., Jiang, W., and Zhou, R. (2019). DAMP-sensing receptors in sterile inflammation and inflammatory diseases. Nat. Rev. Immunol. 20, 95-112. doi: 10.1038/s41577-019-0215-7

Gonzalez-Meljem, J. M., Apps, J. R., Fraser, H. C., and Martinez-Barbera, J. P. (2018). Paracrine roles of cellular senescence in promoting tumourigenesis. $\mathrm{Br}$. J. Cancer 118, 1283-1288. doi: 10.1038/s41416-018-0066-1

Goswami, R., and Awasthi, A. (2020). Editorial: T cell differentiation and function in tissue inflammation. Front. Immunol. 11:289. doi: 10.3389/fimmu.2020. 00289

Guo, H., Callaway, J. B., and Ting, J. P. Y. (2015). Inflammasomes: mechanism of action, role in disease, and therapeutics. Nat. Med. 21, 677-687. doi: 10.1038/ nm.3893

Guo, Y., Gu, R., Gan, D., Hu, F., Li, G., and Xu, G. (2020). Mitochondrial DNA drives noncanonical inflammation activation via cGAS-STING signaling pathway in retinal microvascular endothelial cells. Cell Commun. Signal. 18, 1-12. doi: 10.1186/s12964-020-00637-3

Gurung, C., Fendereski, M., Sapkota, K., Guo, J., Huang, F., and Guo, Y. L. (2021). Dicer represses the interferon response and the double-stranded RNAactivated protein kinase pathway in mouse embryonic stem cells. J. Biol. Chem. 296:100264. doi: 10.1016/J.JBC.2021.100264

Hasegawa, T., Nakashima, M., and Suzuki, Y. (2016). Nuclear DNA damagetriggered NLRP3 inflammasome activation promotes UVB-induced inflammatory responses in human keratinocytes. Biochem. Biophys. Res. Commun. 477, 329-335. doi: 10.1016/J.BBRC.2016.06.106

Hatch, E. M., Fischer, A. H., Deerinck, T. J., and Hetzer, M. W. (2013). Catastrophic nuclear envelope collapse in cancer cell micronuclei. Cell 154, 47-60. doi: 10. 1016/J.CELL.2013.06.007

Hayden, M. S., West, A. P., and Ghosh, S. (2006). NF-кB and the immune response. Oncogene 25, 6758-6780. doi: 10.1038/sj.onc.1209943

He, Y., Hara, H., and Núñez, G. (2016). Mechanism and regulation of NLRP3 inflammasome activation. Trends Biochem. Sci. 41, 1012-1021. doi: 10.1016/j. tibs.2016.09.002

Herranz, N., and Gil, J. (2018). Mechanisms and functions of cellular senescence. J. Clin. Invest. 128, 1238-1246. doi: 10.1172/JCI95148

Hormaechea-Agulla, D., Le, D. T., and King, K. Y. (2020). Common sources of inflammation and their impact on hematopoietic stem cell biology. Curr. Stem Cell Rep. 6, 96-107. doi: 10.1007/s40778-020-00177-z

Hornung, V., Ablasser, A., Charrel-Dennis, M., Bauernfeind, F., Horvath, G., Caffrey, D. R., et al. (2009). AIM2 recognizes cytosolic dsDNA and forms a caspase-1-activating inflammasome with ASC. Nature 458, 514-518. doi: 10. 1038/nature07725

Hu, B., Jin, C., Li, H. B., Tong, J., Ouyang, X., Cetinbas, N. M., et al. (2016). The DNA-sensing AIM2 inflammasome controls radiation-induced cell death and tissue injury. Science 354, 765-768. doi: 10.1126/science.aaf7532

Huang, C.-F., Chen, L., Li, Y.-C., Wu, L., Yu, G.-T., Zhang, W.-F., et al. (2017). NLRP3 inflammasome activation promotes inflammation-induced carcinogenesis in head and neck squamous cell carcinoma. J. Exp. Clin. Cancer Res. 36, 1-13. doi: 10.1186/S13046-017-0589-Y

Iliou, M. S., da Silva-Diz, V., Carmona, F. J., Ramalho-Carvalho, J., Heyn, H., Villanueva, A., et al. (2014). Impaired DICER1 function promotes stemness and metastasis in colon cancer. Oncogene 33:4003. doi: 10.1038/ONC.2013.398

Inomata, K., Aoto, T., Binh, N. T., Okamoto, N., Tanimura, S., Wakayama, T., et al. (2009). Genotoxic stress abrogates renewal of melanocyte stem cells by triggering their differentiation. Cell 137, 1088-1099. doi: 10.1016/J.CELL.2009. 03.037 
Inoue, M., and Shinohara, M. L. (2013). NLRP3 inflammasome and MS/EAE. Autoimmune Dis. 2013:859145. doi: 10.1155/2013/859145

Insinga, A., Cicalese, A., Faretta, M., Gallo, B., Albano, L., Ronzoni, S., et al. (2013). DNA damage in stem cells activates p21, inhibits p53, and induces symmetric self-renewing divisions. Proc. Natl. Acad. Sci. U.S.A. 110, 3931-3936. doi: 10.1073/PNAS.1213394110

Ishikawa, H., and Barber, G. N. (2008). STING is an endoplasmic reticulum adaptor that facilitates innate immune signalling. Nature 455, 674-678. doi: 10.1038/ nature 07317

Ishikawa, H., Ma, Z., and Barber, G. N. (2009). STING regulates intracellular DNAmediated, type i interferon-dependent innate immunity. Nature 461, 788-792. doi: 10.1038 /nature 08476

Jackson, S. P., and Bartek, J. (2009). The DNA-damage response in human biology and disease. Nature 461, 1071-1078. doi: 10.1038/nature08467

Jahandideh, B., Derakhshani, M., Abbaszadeh, H., Akbar Movassaghpour, A., Mehdizadeh, A., Talebi, M., et al. (2020). The pro-inflammatory cytokines effects on mobilization, self-renewal and differentiation of hematopoietic stem cells. Hum. Immunol. 81, 206-217. doi: 10.1016/j.humimm.2020. 01.004

Jefferies, C. A. (2019). Regulating IRFs in IFN driven disease. Front. Immunol. 10:325. doi: $10.3389 /$ fimmu.2019.00325

Jeggo, P. A., Pearl, L. H., and Carr, A. M. (2016). DNA repair, genome stability and cancer: a historical perspective. Nat. Rev. Cancer 16, 35-42. doi: 10.1038/nrc. 2015.4

Jeong, Y. J., Oh, H. K., Park, S. H., and Bong, J. G. (2018). Association between inflammation and cancer stem cell phenotype in breast cancer. Oncol. Lett. 15, 2380-2386. doi: 10.3892/ol.2017.7607

Jiang, X. X., Zhang, Y., Liu, B., Zhang, S. X., Wu, Y., Yu, X. D., et al. (2005). Human mesenchymal stem cells inhibit differentiation and function of monocytederived dendritic cells. Blood 105, 4120-4126. doi: 10.1182/blood-2004-020586

Jones, D. L., and Wagers, A. J. (2008). No place like home: anatomy and function of the stem cell niche. Nat. Rev. Mol. Cell Biol. 9, 11-21. doi: 10.1038/nrm 2319

Jounai, N., Kobiyama, K., Takeshita, F., and Ishii, K. J. (2013). Recognition of damage-associated molecular patterns related to nucleic acids during inflammation and vaccination. Front. Cell. Infect. Microbiol. 2:168. doi: 10.3389/ fcimb. 2012.00168

Kawase-Koga, Y., Low, R., Otaegi, G., Pollock, A., Deng, H., Eisenhaber, F., et al. (2010). RNAase-III enzyme Dicer maintains signaling pathways for differentiation and survival in mouse cortical neural stem cells. J. Cell Sci. 123, 586-594. doi: 10.1242/JCS.059659

Keith, B., and Simon, M. C. (2007). Hypoxia-inducible factors, stem cells, and cancer. Cell 129, 465-472. doi: 10.1016/j.cell.2007.04.019

Kenyon, J., and Gerson, S. L. (2007). The role of DNA damage repair in aging of adult stem cells. Nucleic Acids Res. 35, 7557-7565. doi: 10.1093/NAR/GKM1064

Kingham, E., and Oreffo, R. O. C. (2013). Embryonic and induced pluripotent stem cells: understanding, creating, and exploiting the nano-niche for regenerative medicine. ACS Nano 7:1867. doi: 10.1021/NN3037094

Ko, J. H., Kim, J., Jeong, H. J., Lee, H. J., Youn, J., and Correspondence, O. (2020). Mesenchymal stem and stromal cells harness macrophage-derived amphiregulin to maintain tissue homeostasis. Cell Rep. 30, 3806-3820.e6. doi: 10.1016/j.celrep.2020.02.062

Koltsova, A. S., Pendina, A. A., Efimova, O. A., Chiryaeva, O. G., Kuznetzova, T. V., and Baranov, V. S. (2019). On the complexity of mechanisms and consequences of chromothripsis: an update. Front. Genet. 10:393. doi: 10.3389/FGENE.2019. 00393

Kuehbacher, A., Urbich, C., Zeiher, A. M., and Dimmeler, S. (2007). Role of Dicer and drosha for endothelial microRNA expression and angiogenesis. Circ. Res. 101, 59-68. doi: 10.1161/CIRCRESAHA.107.153916

Kuilman, T., Michaloglou, C., Vredeveld, L. C. W., Douma, S., van Doorn, R., Desmet, C. J., et al. (2008). Oncogene-induced senescence relayed by an interleukin-dependent inflammatory network. Cell 133, 1019-1031. doi: 10. 1016/j.cell.2008.03.039

Kumar, B. V., Connors, T. J., and Farber, D. L. (2018). Human T cell development, localization, and function throughout life. Immunity 48, 202-213. doi: 10.1016/ j.immuni.2018.01.007
Kumar, S., Suman, S., Fornace, A. J., and Datta, K. (2019). Intestinal stem cells acquire premature senescence and senescence associated secretory phenotype concurrent with persistent DNA damage after heavy ion radiation in mice. Aging 11, 4145-4158. doi: 10.18632/aging.102043

Kuriakose, T., and Kanneganti, T. D. (2018). ZBP1: innate sensor regulating cell death and inflammation. Trends Immunol. 39, 123-134. doi: 10.1016/j.it.2017. 11.002

Kwon, M., Leibowitz, M. L., and Lee, J.-H. (2020). Small but mighty: the causes and consequences of micronucleus rupture. Exp. Mol. Med. 52, 1777-1786. doi: 10.1038/s12276-020-00529-z

Lane, S. W., Williams, D. A., and Watt, F. M. (2014). Modulating the stem cell niche for tissue regeneration. Nat. Biotechnol. 32, 795-803. doi: 10.1038/nbt.2978

Lee, A. J., and Ashkar, A. A. (2018). The dual nature of type I and type II interferons. Front. Immunol. 9:2061. doi: 10.3389/fimmu.2018.02061

Lee, A. K., Pan, D., Bao, X., Hu, M., Li, F., and Li, C. Y. (2020). Endogenous retrovirus activation as a key mechanism of anti-tumor immune response in radiotherapy. Radiat. Res. 193, 305-317. doi: 10.1667/RADE-20-00013

Lee, C.-L., Blum, J. M., and Kirsch, D. G. (2013). Role of p53 in regulating tissue response to radiation by mechanisms independent of apoptosis. Transl. Cancer Res. 2, 412-421. doi: 10.21037/1638

Li, C., Liu, W., Wang, F., Hayashi, T., Mizuno, K., Hattori, S., et al. (2021). DNA damage-triggered activation of cGAS-STING pathway induces apoptosis in human keratinocyte HaCaT cells. Mol. Immunol. 131, 180-190. doi: 10.1016/ J.MOLIMM.2020.12.037

Li, D., Wu, R., Guo, W., Xie, L., Qiao, Z., Chen, S., et al. (2019). STING-mediated IFI16 degradation negatively controls type I interferon production. Cell Rep. 29, 1249-1260.e4. doi: 10.1016/j.celrep.2019.09.069

Li, L., Li, L., Zhang, Z., and Jiang, Z. (2015). Hypoxia promotes bone marrowderived mesenchymal stem cell proliferation through apelin/APJ/autophagy pathway. Acta Biochim. Biophys. Sin. 47, 362-367. doi: 10.1093/abbs/ gmv014

Li, T., and Chen, Z. J. (2018). The cGAS-cGAMP-STI NG pathway connects DNA damage to inflammation, senescence, and cancer. J. Exp. Med. 215, 1287-1299. doi: 10.1084/jem.20180139

Li, W., Lu, L., Lu, J., Wang, X., Yang, C., Jin, J., et al. (2020). cGAS-STING-mediated DNA sensing maintains CD8+ $\mathrm{T}$ cell stemness and promotes antitumor T cell therapy. Sci. Transl. Med. 12:eaay9013. doi: 10.1126/scitranslmed.aay 9013

Liao, W., Du, C., and Wang, J. (2020). The cGAS-STING pathway in hematopoiesis and its physiopathological significance. Front. Immunol. 11:573915. doi: 10. 3389/fimmu.2020.573915

Lin, J.-Y., Kuo, R.-L., and Huang, H.-I. (2019). Activation of type I interferon antiviral response in human neural stem cells. Stem Cell Res. Ther. 10, 1-17. doi: 10.1186/S13287-019-1521-5

Liu, T., Zhang, L., Joo, D., and Sun, S. C. (2017). NF-kB signaling in inflammation. Signal Transduct. Target. Ther. 2:17023. doi: 10.1038/sigtrans.2017.23

Liu, X., Zhang, Z., Ruan, J., Pan, Y., Magupalli, V. G., Wu, H., et al. (2016). Inflammasome-activated gasdermin $\mathrm{D}$ causes pyroptosis by forming membrane pores. Nature 535, 153-158. doi: 10.1038/nature18629

Low, M., Eisner, C., and Rossi, F. (2017). "Fibro/adipogenic progenitors (FAPs): isolation by FACS and culture," in Methods in Molecular Biology, eds E. Perdiguero and D. Cornelison (New York, NY: Humana Press Inc.), 179-189. doi: 10.1007/978-1-4939-6771-1_9

Lu, H., Clauser, K. R., Tam, W. L., Fröse, J., Ye, X., Eaton, E. N., et al. (2014). A breast cancer stem cell niche supported by juxtacrine signalling from monocytes and macrophages. Nat. Cell Biol. 16, 1105-1117. doi: 10.1038/ncb 3041

Luna, J. I., Grossenbacher, S. K., Murphy, W. J., and Canter, R. J. (2017). Targeting cancer stem cells with natural killer cell immunotherapy. Expert Opin. Biol. Ther. 17, 313-324. doi: 10.1080/14712598.2017.1271874

MacDonald, E. S., and Barrett, J. G. (2020). The potential of mesenchymal stem cells to treat systemic inflammation in horses. Front. Vet. Sci. 6:507. doi: 10 3389/fvets.2019.00507

MacKenzie, K. J., Carroll, P., Martin, C. A., Murina, O., Fluteau, A., Simpson, D. J., et al. (2017). CGAS surveillance of micronuclei links genome instability to innate immunity. Nature 548, 461-465. doi: 10.1038/nature 23449 
Madabhushi, R., Pan, L., and Tsai, L. H. (2014). DNA damage and its links to neurodegeneration. Neuron 83, 266-282. doi: 10.1016/j.neuron.2014.06.034

Maekawa, H., Inoue, T., Ouchi, H., Jao, T., Inoue, R., Nishi, H., et al. (2019). Mitochondrial damage causes inflammation via cGAS-STING signaling in acute kidney injury. Cell Rep. 29, 1261-1273. doi: 10.1016/j.celrep.2019.09.050

Maldonado-Lasunción, I., Verhaagen, J., and Oudega, M. (2018). Mesenchymal stem cell-macrophage choreography supporting spinal cord repair. Neurotherapeutics 15, 578-587. doi: 10.1007/s13311-018-0629-0

Man, S. M., Zhu, Q., Zhu, L., Liu, Z., Karki, R., Malik, A., et al. (2015). Critical role for the DNA sensor AIM2 in stem cell proliferation and cancer. Cell 162, 45-58. doi: 10.1016/J.CELL.2015.06.001

Mandal, P., Blanpain, C., and Rossi, D. (2011). DNA damage response in adult stem cells: pathways and consequences. Nat. Rev. Mol. Cell Biol. 12, 198-202. doi: 10.1038/NRM3060

Marmary, Y., Adar, R., Gaska, S., Wygoda, A., Maly, A., Cohen, J., et al. (2016). Radiation-induced loss of salivary gland function is driven by cellular senescence and prevented by IL6 modulation. Cancer Res. 76, 1170-1180. doi: 10.1158/0008-5472.CAN-15-1671

Martin-Hijano, L., and Sainz, B. (2020). The interactions between cancer stem cells and the innate interferon signaling pathway. Front. Immunol. 11:526. doi: $10.3389 /$ fimmu.2020.00526

Matatall, K. A., Shen, C. C., Challen, G. A., and King, K. Y. (2014). Type II interferon promotes differentiation of myeloid-biased hematopoietic stem cells. Stem Cells 32, 3023-3030. doi: 10.1002/stem.1799

Matsumura, H., Mohri, Y., Binh, N. T., Morinaga, H., Fukuda, M., Ito, M., et al. (2016). Hair follicle aging is driven by transepidermal elimination of stem cells via COL17A1 proteolysis. Science 351:aad4395. doi: 10.1126/SCIENCE. AAD4395

McBride, W. H., and Schaue, D. (2020). Radiation-induced tissue damage and response. J. Pathol. 250, 647-655. doi: 10.1002/path.5389

McCabe, A., and MacNamara, K. C. (2016). Macrophages: key regulators of steadystate and demand-adapted hematopoiesis. Exp. Hematol. 44, 213-222. doi: 10. 1016/j.exphem.2016.01.003

McLaughlin, M., Patin, E. C., Pedersen, M., Wilkins, A., Dillon, M. T., Melcher, A. A., et al. (2020). Inflammatory microenvironment remodelling by tumour cells after radiotherapy. Nat. Rev. Cancer 20, 203-217. doi: 10.1038/s41568-0200246-1

Mendelson, A., and Frenette, P. S. (2014). Hematopoietic stem cell niche maintenance during homeostasis and regeneration. Nat. Med. 20, 833-846. doi: $10.1038 / \mathrm{nm} .3647$

Mijit, M., Caracciolo, V., Melillo, A., Amicarelli, F., and Giordano, A. (2020). Role of p53 in the regulation of cellular senescence. Biomolecules 10:420. doi: 10.3390/BIOM10030420

Milanovic, M., Fan, D. N. Y., Belenki, D., Däbritz, J. H. M., Zhao, Z., Yu, Y., et al. (2018). Senescence-associated reprogramming promotes cancer stemness. Nature 553, 96-100. doi: 10.1038/nature25167

Moiseeva, O., Mallette, F. A., Mukhopadhyay, U. K., Moores, A., and Ferbeyre, G. (2006). DNA damage signaling and p53-dependent senescence after prolonged $\beta$-interferon stimulation. Mol. Biol. Cell 17, 1583-1592. doi: 10.1091/mbc.E0509-0858

Mosteiro, L., Pantoja, C., de Martino, A., and Serrano, M. (2018). Senescence promotes in vivo reprogramming through p16 INK4a and IL-6. Aging Cell 17:e12711. doi: 10.1111/acel.12711

Much, C., Auchynnikava, T., Pavlinic, D., Buness, A., Rappsilber, J., Benes, V., et al. (2016). Endogenous mouse Dicer is an exclusively cytoplasmic protein. PLoS Genet. 12:e1006095. doi: 10.1371/JOURNAL.PGEN.1006095

Mussil, B., Suspène, R., Caval, V., Durandy, A., Wain-Hobson, S., and Vartanian, J. P. (2019). Genotoxic stress increases cytoplasmic mitochondrial DNA editing by human APOBEC3 mutator enzymes at a single cell level. Sci. Rep. 9:3109. doi: 10.1038/s41598-019-39245-8

Naik, S., Larsen, S. B., Cowley, C. J., and Fuchs, E. (2018). Two to Tango: dialog between immunity and stem cells in health and disease. Cell 175, 908-920. doi: 10.1016/j.cell.2018.08.071

Naik, S., Larsen, S. B., Gomez, N. C., Alaverdyan, K., Sendoel, A., Yuan, S., et al. (2017). Inflammatory memory sensitizes skin epithelial stem cells to tissue damage. Nature 550, 475-480. doi: 10.1038/nature24271

Nakad, R., and Schumacher, B. (2016). DNA damage response and immune defense: links and mechanisms. Front. Genet. 7:147. doi: 10.3389/fgene.2016. 00147
Netea, M. G., Domínguez-Andrés, J., Barreiro, L. B., Chavakis, T., Divangahi, M., Fuchs, E., et al. (2020). Defining trained immunity and its role in health and disease. Nat. Rev. Immunol. 20, 375-388. doi: 10.1038/s41577-020-0285-6

Nicaise, A. M., Wagstaff, L. J., Willis, C. M., Paisie, C., Chandok, H., Robson, P., et al. (2019). Cellular senescence in progenitor cells contributes to diminished remyelination potential in progressive multiple sclerosis. Proc. Natl. Acad. Sci. U.S.A. 116, 9030-9039. doi: 10.1073/pnas. 1818348116

Onomoto, K., Onoguchi, K., and Yoneyama, M. (2021). Regulation of RIG-I-like receptor-mediated signaling: interaction between host and viral factors. Cell. Mol. Immunol. 18, 539-555. doi: 10.1038/s41423-020-00602-7

Orvain, C., Lin, Y.-L., Jean-Louis, F., Hocini, H., Hersant, B., Bennasser, Y., et al. (2020). Hair follicle stem cell replication stress drives IFI16/STING-dependent inflammation in hidradenitis suppurativa. J. Clin. Invest. 130:3777. doi: 10.1172/ JCI131180

Paludan, S. R., and Bowie, A. G. (2013). Immune sensing of DNA. Immunity 38, 870-880. doi: 10.1016/j.immuni.2013.05.004

Park, E. J., Shimaoka, M., and Kiyono, H. (2017). MicroRNA-mediated dynamic control of mucosal immunity. Int. Immunol. 29, 157-163. doi: 10.1093/ INTIMM/DXX019

Passos, J. F., Saretzki, G., Ahmed, S., Nelson, G., Richter, T., Peters, H., et al. (2007). Mitochondrial dysfunction accounts for the stochastic heterogeneity in telomere-dependent senescence. PLoS Biol. 5:e110. doi: 10.1371/journal.pbio. 0050110

Pazhanisamy, S. K. (2009). Stem cells, DNA damage, ageing and cancer. Hematol. Oncol. Stem Cell Ther. 2, 375-384. doi: 10.1016/S1658-3876(09)50005-2

Peng, X., Wu, Y., Brouwer, U., van Vliet, T., Wang, B., Demaria, M., et al. (2020). Cellular senescence contributes to radiation-induced hyposalivation by affecting the stem/progenitor cell niche. Cell Death Dis. 11:854. doi: 10.1038/ s41419-020-03074-9

Pennings, S., Liu, K. J., and Qian, H. (2018). The stem cell niche: Interactions between stem cells and their environment. Stem Cells Int. 2018:4879379. doi: $10.1155 / 2018 / 4879379$

Piccaluga, P. P., Agostinelli, C., Fuligni, F., Righi, S., Tripodo, C., Re, M. C., et al. (2015). IFI16 expression is related to selected transcription factors during B-cell differentiation. J. Immunol. Res. doi: 10.1155/2015/747645

Ping, Z., Chen, S., Hermans, S. J. F., Kenswil, K. J. G., Feyen, J., van Dijk, C., et al. (2019). Activation of NF-кB driven inflammatory programs in mesenchymal elements attenuates hematopoiesis in low-risk myelodysplastic syndromes. Leukemia 33, 536-541. doi: 10.1038/s41375-018-0267-x

Pinho, S., and Frenette, P. S. (2019). Haematopoietic stem cell activity and interactions with the niche. Nat. Rev. Mol. Cell Biol. 20, 303-320. doi: 10.1038/ s41580-019-0103-9

Platanitis, E., and Decker, T. (2018). Regulatory networks involving STATs, IRFs, and NFKB in inflammation. Front. Immunol. 9:2542. doi: 10.3389/fimmu.2018. 02542

Poirier, E. Z., Buck, M. D., Chakravarty, P., Carvalho, J., Frederico, B., Cardoso, A., et al. (2021). An isoform of Dicer protects mammalian stem cells against multiple RNA viruses. Science 373, 231-236. doi: 10.1126/SCIENCE.ABG2264

Pronk, C. J. H., Veiby, O. P., Bryder, D., and Jacobsen, S. E. W. (2011). Tumor necrosis factor restricts hematopoietic stem cell activity in mice: involvement of two distinct receptors. J. Exp. Med. 208, 1563-1570. doi: 10.1084/JEM. 20110752

Qian, P., He, X. C., Paulson, A., Li, Z., Tao, F., Perry, J. M., et al. (2016). The Dlk1-Gtl2 locus preserves LT-HSC function by inhibiting the PI3K-mTOR pathway to restrict mitochondrial metabolism. Cell Stem Cell 18, 214-228. doi: 10.1016/J.STEM.2015.11.001

Rehwinkel, J., and Gack, M. U. (2020). RIG-I-like receptors: their regulation and roles in RNA sensing. Nat. Rev. Immunol. 20, 537-551. doi: 10.1038/s41577020-0288-3

Riley, J. S., and Tait, S. W. (2020). Mitochondrial DNA in inflammation and immunity. EMBO Rep. 21:e49799. doi: 10.15252/embr.201949799

Ritschka, B., Storer, M., Mas, A., Heinzmann, F., Ortells, M. C., Morton, J. P., et al. (2017). The senescence-associated secretory phenotype induces cellular plasticity and tissue regeneration. Genes Dev. 31, 172-183. doi: 10.1101/gad. 290635.116

Sagulenko, V., Thygesen, S., Sester, D., Idris, A., Cridland, J. A., Vajihala, P. R., et al. (2013). AIM2 and NLRP3 inflammasomes activate both apoptotic and pyroptotic death pathways via ASC. Cell Death Differ. 20, 1149-1160. doi: $10.1038 /$ cdd. 2013.37 
Saito, Y., Chikenji, T. S., Matsumura, T., Nakano, M., and Fujimiya, M. (2020). Exercise enhances skeletal muscle regeneration by promoting senescence in fibro-adipogenic progenitors. Nat. Commun. 11:889. doi: 10.1038/s41467-02014734-x

Sato, T., Onai, N., Yoshihara, H., Arai, F., Suda, T., and Ohteki, T. (2009). Interferon regulatory factor-2 protects quiescent hematopoietic stem cells from type i interferon-dependent exhaustion. Nat. Med. 15, 696-700. doi: 10.1038/ nm. 1973

Scadden, D. T. (2006). The stem-cell niche as an entity of action. Nature 441, 1075-1079. doi: 10.1038/nature04957

Schroder, K., and Tschopp, J. (2010). The inflammasomes. Cell 140, 821-832. doi: 10.1016/j.cell.2010.01.040

Schumacher, B., Pothof, J., Vijg, J., and Hoeijmakers, J. H. J. (2021). The central role of DNA damage in the ageing process. Nature 592, 695-703. doi: 10.1038/ s41586-021-03307-7

Scully, R., Panday, A., Elango, R., and Willis, N. A. (2019). DNA double-strand break repair-pathway choice in somatic mammalian cells. Nat. Rev. Mol. Cell Biol. 20, 698-714. doi: 10.1038/s41580-019-0152-0

Seldin, L., and Macara, I. G. (2020). DNA damage promotes epithelial hyperplasia and fate mis-specification via fibroblast inflammasome activation. Dev. Cell 55, 558-573.e6. doi: 10.1016/j.devcel.2020.09.021

Sémont, A., François, S., Mouiseddine, M., François, A., Saché, A., Frick, J., et al. (2006). Mesenchymal stem cells increase self-renewal of small intestinal epithelium and accelerate structural recovery after radiation injury. Adv. Exp. Med. Biol. 585, 19-30. doi: 10.1007/978-0-387-34133-0_2

Seyfried, A. N., Maloney, J. M., and MacNamara, K. C. (2020). Macrophages orchestrate hematopoietic programs and regulate HSC function during inflammatory stress. Front. Immunol. 11:1499. doi: 10.3389/fimmu.2020. 01499

Shang, D., Yang, P., Liu, Y., Song, J., Zhang, F., and Tian, Y. (2011). Interferon- $\alpha$ induces G1 cell-cycle arrest in renal cell carcinoma cells via activation of Jak-Stat signaling. Cancer Invest. 29, 347-352. doi: 10.3109/07357907.2011.568566

Shao, L., Feng, W., Li, H., Gardner, D., Luo, Y., Wang, Y., et al. (2014). Total body irradiation causes long-term mouse BM injury via induction of HSC premature senescence in an Ink4a-and Arf-independent manner. Blood 123, 3105-3115. doi: 10.1182/blood-2013-07

Sharma, M., Rajendrarao, S., Shahani, N., Ramírez-Jarquín, U. N., and Subramaniam, S. (2020). Cyclic GMP-AMP synthase promotes the inflammatory and autophagy responses in Huntington disease. Proc. Natl. Acad. Sci. U.S.A. 117, 15989-15999. doi: 10.1073/PNAS.2002144117

Sharma, M., and de Alba, E. (2021). Structure, activation and regulation of NLRP3 and AIM2 inflammasomes. Int. J. Mol. Sci. 22:872. doi: 10.3390/ijms22020872

Shevde, N. (2012). Stem cells: flexible friends. Nature 483, S22-S26. doi: 10.1038/ $483 \mathrm{~s} 22 \mathrm{a}$

Shi, Y., Ping, Y. F., Zhou, W., He, Z. C., Chen, C., Bian, B. S. J., et al. (2017). Tumour-associated macrophages secrete pleiotrophin to promote PTPRZ1 signalling in glioblastoma stem cells for tumour growth. Nat. Commun. 8:15080. doi: $10.1038 /$ ncomms 15080

Shin, T.-H., Kim, H.-S., Choi, S. W., and Kang, K.-S. (2017). Mesenchymal stem cell therapy for inflammatory skin diseases: clinical potential and mode of action. Int. J. Mol. Sci. 18:244. doi: 10.3390/IJMS18020244

Silva-Gomes, S., Decout, A., and Nigou, J. (2014). "Pathogen-associated molecular patterns (PAMPs)," in Encyclopedia of Inflammatory Diseases, ed. M. Parnham (Basel: Birkhäuser), 1-16. doi: 10.1007/978-3-0348-0620-6_35-1

Singh, G., Pachouri, U. C., Khaidem, D. C., Kundu, A., Chopra, C., and Singh, P. (2015). Mitochondrial DNA damage and diseases. F1000Res. 4:176. doi: 10.12688/f1000research.6665.1

Sotiropoulou, P. A., Candi, A., Mascré, G., De Clercq, S., Youssef, K. K., Lapouge, G., et al. (2010). Bcl-2 and accelerated DNA repair mediates resistance of hair follicle bulge stem cells to DNA-damage-induced cell death. Nat. Cell Biol. 12, 572-582. doi: 10.1038/ncb2059

Strowig, T., Henao-Mejia, J., Elinav, E., and Flavell, R. (2012). Inflammasomes in health and disease. Nature 481, 278-286. doi: 10.1038/nature10759

Sullivan, C. B., Porter, R. M., Evans, C. H., Ritter, T., Shaw, G., Barry, F., et al. (2014). TNF $\alpha$ and IL- $1 \beta$ influence the differentiation and migration of murine MSCs independently of the NF-кB pathway. Stem Cell Res. Ther. 5:104. doi: $10.1186 /$ scrt492
Takaoka, A., Wang, Z., Choi, M. K., Yanai, H., Negishi, H., Ban, T., et al. (2007). DAI (DLM-1/ZBP1) is a cytosolic DNA sensor and an activator of innate immune response. Nature 448, 501-505. doi: 10.1038/nature 06013

Tallerico, R., Conti, L., Lanzardo, S., Sottile, R., Garofalo, C., Wagner, A. K., et al. (2017). NK cells control breast cancer and related cancer stem cell hematological spread. Oncoimmunology 6:e1284718. doi: 10.1080/2162402X. 2017.1284718

Tigano, M., Vargas, D. C., Tremblay-Belzile, S., Fu, Y., and Sfeir, A. (2021). Nuclear sensing of breaks in mitochondrial DNA enhances immune surveillance. Nature 591, 477-481. doi: 10.1038/s41586-021-03269-w

Tiwari, V., and Wilson III, D. M. (2019). DNA damage and associated DNA repair defects in disease and premature aging. Am. J. Hum. Genet. 105, 237-257. doi: 10.1016/j.ajhg.2019.06.005

Tulotta, C., Lefley, D. V., Freeman, K., Gregory, W. M., Hanby, A. M., Heath, P. R., et al. (2019). Endogenous production of IL1B by breast cancer cells drives metastasis and colonization of the bone microenvironment. Clin. Cancer Res. 25, 2769-2782. doi: 10.1158/1078-0432.CCR-18-2202

Vallés, G., Bensiamar, F., Maestro-Paramio, L., García-Rey, E., Vilaboa, N., and Saldaña, L. (2020). Influence of inflammatory conditions provided by macrophages on osteogenic ability of mesenchymal stem cells. Stem Cell Res. Ther. 11:57. doi: 10.1186/s13287-020-1578-1

Van Gorp, H., and Lamkanfi, M. (2019). The emerging roles of inflammasome-dependent cytokines in cancer development. EMBO Rep. 20:e47575. doi: 10.15252/embr.201847575

Vescovi, A. L., Galli, R., and Reynolds, B. A. (2006). Brain tumour stem cells. Nat. Rev. Cancer 6, 425-436. doi: 10.1038/nrc1889

Viola, A., Munari, F., Sánchez-Rodríguez, R., Scolaro, T., and Castegna, A. (2019). The metabolic signature of macrophage responses. Front. Immunol. 10:1462. doi: 10.3389/fimmu.2019.01462

Vishlaghi, N., and Lisse, T. S. (2020). Dicer- and bulge stem cell-dependent microRNAs during induced anagen hair follicle development. Front. Cell Dev. Biol. 8:338. doi: 10.3389/FCELL.2020.00338

Vitale, I., Manic, G., De Maria, R., Kroemer, G., and Galluzzi, L. (2017). DNA damage in stem cells. Mol. Cell 66, 306-319. doi: 10.1016/J.MOLCEL.2017.04. 006

Vivier, E., and Malissen, B. (2005). Innate and adaptive immunity: specificities and signaling hierarchies revisited. Nat. Immunol. 6, 17-21. doi: 10.1038/ni1153

Vogt, N. (2021). Assembloids. Nat. Methods 18:27. doi: 10.1038/s41592-02001026-x

Vono, R., Garcia, E. J., Spinetti, G., and Madeddu, P. (2018). Oxidative stress in mesenchymal stem cell senescence: regulation by coding and noncoding RNAs. Antioxid. Redox Signal. 29, 864-879. doi: 10.1089/ARS.2017.7294

Voog, J., and Jones, D. L. (2010). Stem cells and the niche: a dynamic duo. Cell Stem Cell 6, 103-115. doi: 10.1016/j.stem.2010.01.011

Wagers, A. J., and Weissman, I. L. (2004). Plasticity of adult stem cells. Cell 116, 639-648. doi: 10.1016/S0092-8674(04)00208-9

Wang, R., Li, H., Wu, J., Cai, Z.-Y., Li, B., Ni, H., et al. (2020). Gut stem cell necroptosis by genome instability triggers bowel inflammation. Nature 580, 386-390. doi: 10.1038/s41586-020-2127-x

Wei, J., Wang, H., Wang, H., Wang, B., Meng, L., Xin, Y., et al. (2019). The role of NLRP3 inflammasome activation in radiation damage. Biomed. Pharmacother. 118:109217. doi: 10.1016/j.biopha.2019.109217

White, E., Schlackow, M., Kamieniarz-Gdula, K., Proudfoot, N. J., and Gullerova, M. (2014). Human nuclear Dicer restricts the deleterious accumulation of endogenous double-stranded RNA. Nat. Struct. Mol. Biol. 21, 552-559. doi: $10.1038 / \mathrm{nsmb} .2827$

Widera, D., Kaus, A., Kaltschmidt, C., and Kaltschmidt, B. (2008). Neural stem cells, inflammation and NF-кB: basic principle of maintenance and repair or origin of brain tumours? Neuroscience review series. J. Cell. Mol. Med. 12, 459-470. doi: 10.1111/j.1582-4934.2007.00208.x

Wiley, C., Velarde, M., Lecot, P., Liu, S., Sarnoski, E., Freund, A., et al. (2016). Mitochondrial dysfunction induces senescence with a distinct secretory phenotype. Cell Metab. 23, 303-314. doi: 10.1016/J.CMET.2015. 11.011

Winkler, I. G., Sims, N. A., Pettit, A. R., Barbier, V., Nowlan, B., Helwani, F., et al. (2010). Bone marrow macrophages maintain hematopoietic stem cell 
(HSC) niches and their depletion mobilizes HSCs. Blood 116, 4815-4828. doi: 10.1182/blood-2009-11-253534

Wu, Q., Liu, J., Wang, X., Feng, L., Wu, J., Zhu, X., et al. (2020). Organ-on-achip: recent breakthroughs and future prospects. Biomed. Eng. OnLine 19, 1-19. doi: $10.1186 /$ S12938-020-0752-0

Xia, P., Wang, S., Gao, P., Gao, G., and Fan, Z. (2016). DNA sensor cGAS-mediated immune recognition. Protein Cell 7, 777-791. doi: 10.1007/s13238-016-0320-3

Yang, H., Wang, H., Ren, U., Chen, Q., and Chena, Z. J. (2017). CGAS is essential for cellular senescence. Proc. Natl. Acad. Sci. U.S.A. 114, E4612-E4620. doi: 10.1073/pnas. 1705499114

Yang, K., Wang, J., Wu, M., Li, M., Wang, Y., and Huang, X. (2015). Mesenchymal stem cells detect and defend against gammaherpesvirus infection via the cGASSTING pathway. Sci. Rep. 5:7820. doi: 10.1038/srep07820

Yang, K., Wang, J., Xiang, A. P., Zhan, X., Wang, Y., Wu, M., et al. (2013). Functional RIG-I-like receptors control the survival of mesenchymal stem cells. Cell Death Dis. 4:e967. doi: 10.1038/CDDIS.2013.504

Yin, Y., Zhou, Z., Liu, W., Chang, Q., Sun, G., and Dai, Y. (2017). Vascular endothelial cells senescence is associated with NOD-like receptor family pyrin domain-containing 3 (NLRP3) inflammasome activation via reactive oxygen species (ROS)/thioredoxin-interacting protein (TXNIP) pathway. Int. J. Biochem. Cell Biol. 84, 22-34. doi: 10.1016/j.biocel.2017.01.001

Yu, Q., Katlinskaya, Y. V., Carbone, C. J., Zhao, B., Katlinski, K. V., Zheng, H., et al. (2015). DNA-damage-induced type I interferon promotes senescence and inhibits stem cell function. Cell Rep. 11, 785-797. doi: 10.1016/j.celrep.2015. 03.069

Yum, S., Li, M., Fang, Y., and Chen, Z. J. (2021). TBK1 recruitment to STING activates both IRF3 and NF- $\kappa B$ that mediate immune defense against tumors and viral infections. Proc. Natl. Acad. Sci. U.S.A. 118:2100225118. doi: 10.1073/ pnas. 2100225118

Zhang, D., Liu, C., Li, H., and Jiao, J. (2020). Deficiency of STING signaling in embryonic cerebral cortex leads to neurogenic abnormalities and autistic-like behaviors. Adv. Sci. 7:2002117. doi: 10.1002/advs.202002117
Zhang, H., Menzies, K. J., and Auwerx, J. (2018). The role of mitochondria in stem cell fate and aging. Development 145:dev143420. doi: 10.1242/DEV.143420

Zhang, S., Yang, X., Wang, L., and Zhang, C. (2018). Interplay between inflammatory tumor microenvironment and cancer stem cells (Review). Oncol. Lett. 16, 679-686. doi: 10.3892/ol.2018.8716

Zhao, C., and Zhao, W. (2020). NLRP3 inflammasome-A key player in antiviral responses. Front. Immunol. 11:211. doi: 10.1016/j.jhep.2016.12.018

Zhao, X., Xie, L., Wang, Z., Wang, J., Xu, H., Han, X., et al. (2020). ZBP1 (DAI/DLM-1) promotes osteogenic differentiation while inhibiting adipogenic differentiation in mesenchymal stem cells through a positive feedback loop of Wnt/B-catenin signaling. Bone Res. 8:12. doi: 10.1038/s41413-020-0085-4

Zheng, Z., Jia, S., Shao, C., and Shi, Y. (2020). Irradiation induces cancer lung metastasis through activation of the cGAS-STING-CCL5 pathway in mesenchymal stromal cells. Cell Death Dis. 11:326. doi: 10.1038/s41419-0202546-5

Conflict of Interest: The authors declare that the research was conducted in the absence of any commercial or financial relationships that could be construed as a potential conflict of interest.

Publisher's Note: All claims expressed in this article are solely those of the authors and do not necessarily represent those of their affiliated organizations, or those of the publisher, the editors and the reviewers. Any product that may be evaluated in this article, or claim that may be made by its manufacturer, is not guaranteed or endorsed by the publisher.

Copyright (c) 2021 Cinat, Coppes and Barazzuol. This is an open-access article distributed under the terms of the Creative Commons Attribution License (CC BY). The use, distribution or reproduction in other forums is permitted, provided the original author(s) and the copyright owner(s) are credited and that the original publication in this journal is cited, in accordance with accepted academic practice. No use, distribution or reproduction is permitted which does not comply with these terms. 